\title{
Article
}

\section{Exploring Nanotechnologies for the Effective Therapy of Malaria using Plant- Based Medicines}

Oga, Enoche Florence and Singh, Kamalinder

Available at https://clok.uclan.ac.uk/14544/

Oga, Enoche Florence orcid iconORCID: 0000-0002-2661-0574 and Singh, Kamalinder orcid iconORCID: 0000-0001-7325-0711 (2016) Exploring Nanotechnologies for the Effective Therapy of Malaria using Plant-Based Medicines. Current Pharmaceutical Design, 22 (27). pp. 4232-4246. ISSN $1381-6128$

It is advisable to refer to the publisher's version if you intend to cite from the work. http://dx.doi.org/10.2174/1381612822666160603014511

For more information about UCLan's research in this area go to http://www.uclan.ac.uk/researchgroups/ and search for < name of research Group>.

For information about Research generally at UCLan please go to http://www.uclan.ac.uk/research/

All outputs in CLoK are protected by Intellectual Property Rights law, including Copyright law. Copyright, IPR and Moral Rights for the works on this site are retained by the individual authors and/or other copyright owners. Terms and conditions for use of this material are defined in the policies page.

\section{CLoK}

Central Lancashire online Knowledge www.clok.uclan.ac.uk

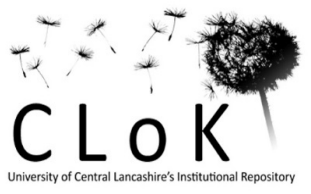




\title{
Exploring Nanotechnologies for the Effective
}

\section{Therapy of Malaria using Plant-Based Medicines}

\author{
Enoche F. Oga and Kamalinder K. Singh*
}

School of Pharmacy and Biomedical Sciences,

University of Central Lancashire, Preston, PR1 2HE, United Kingdom

*Author to whom correspondence should be made:

Professor Kamalinder K. Singh

School of Pharmacy and Biomedical Sciences

University of Central Lancashire

United Kingdom

Email: KSingh1@uclan.ac.uk 


\begin{abstract}
Malaria is a potentially lethal disease caused by species of the plasmodium parasite. Despite the advances in the interventions for its control and approaches to manage its fatality, morbidity and mortality rates are still high. At present, artemisinin-based combination therapy is the first line of treatment. However, there is the need to explore newer approaches as reduced effectiveness and multi-drug resistance (even to artemisinin) has been reported in some regions and is expected to widen in scope. Phytomedicines have shown promise for the management of this debilitating disease and there are abundant resources in most of the areas where this disease is endemic. This report would systematically review the literature, emphasizing the challenges encountered in the control of malaria, active phytochemicals currently utilised in the management, drug delivery approaches as well as the nanotechnology-based systems that could be exploited in its treatment. These phytomedicines, either delivered conventionally or via the use of advanced delivery systems may suggest new strategies towards the better management of malaria.
\end{abstract}

Keywords: malaria, phytomedicine, drug delivery, nanotechnology

\title{
Abbreviations:
}

ACT, artemisinin-based combination therapy; AUC, area under the plasma concentration-time curve; CNT, carbon nanotubes; HPMA, N-(2-hydroxypropyl) methacrylamide copolymer; IC 50 , 50\% inhibitory concentration; ITM, improved traditional medicines; LLIN, long lasting insecticidal nets; LUV, large unilamellar vesicles; MLV, multilamellar vesicles; MWCNT, multi-walled carbon nanotubes; NLC, nanostructured lipid carriers; PAMAM, polyamidoamine; PEG, polyethylene glycol; PLA, poly lactic acid; PLGA, poly (lactic-co-glycolic acid); PGA, polyglutamic acid; PPI, polypropyleneimine; RBC, red blood cells; SLN, solid lipid nanoparticles; SMEDDS, self microemulsifying drug delivery systems; SWCNT, single-walled carbon nanotubes; Tmax, time to peak concentration; TPGS, d- $\alpha$-Tocopheryl polyethylene glycol 1000 succinate 


\section{INTRODUCTION}

\subsection{THE DISEASE 'MALARIA'}

Malaria is a debilitating disease, widespread in many tropical and subtropical regions. WHO ascribed over half a million deaths to the disease in 2013. In humans, this lethal mosquito-borne disease is caused by the plasmodium species; Plasmodium falciparum, Plasmodium vivax, Plasmodium malariae and Plasmodium ovale with Plasmodium falciparum responsible for the most fatalites. Despite its current high mortality, it has been demonstrated that global health initiatives continue to make progress in reducing its cases and deaths.

Increased resistance to currently used antimalarial therapies signifies an urgent need to discover and develop novel drugs alongside more effective drug delivery systems. Plants are widely used as a first line remedy for the infection in malaria-endemic areas, with reports of up to $80 \%$ of the local population in some developing countries dependent on these as their primary source of healthcare [1]. Willcox and Bodeker [2] prepared a database with 1277 plant species from 160 families being used to treat malaria or fever. With the resurgence in the interest and use of plant medicines as well as more plants being discovered for malaria treatment, this figure is presently thought to be higher. However, despite their popular use, an important drawback of these phytomedicines is their need for proper standardisation and assurance of quality, safety and efficacy.

Although WHO recommends artemisinin-based combination therapy (ACT) as the drugs of choice for uncomplicated malaria, some current conventional pharmaceuticals used to manage this debilitating disease are known to have low bioavailability and adverse side effects. This is in addition to limitations and complications presented by increased resistance to conventional therapy by the parasites and multiple dosage regimens that reduce patient adherence etc. This is coupled with the narrow therapeutic index of some of the drugs, posing potential for toxicity when administered in the traditional form. Primaquine recommended in combination with ACTs to reduce transmissibility of vivax malaria could cause haemolytic anaemia in patients with glucose-6-phosphate dehydrogenase deficiency. Chloroquine used for treating uncomplicated knowlesi, malariae, ovale or vivax plasmodium infection, while quinine and clindamycin recommended for certain special 
risk groups have been reported to cause adverse effects including dizziness, skin rashes, sleep disturbances, agranulocytosis, risks of cardiac, neurological toxicity and neuropsychiatric reactions among others [3-5]. Looking at these limitations there arise a definite need for viable alternatives to current antimalarial therapy.

Delivering drugs on the nanoscale confers numerous potential advantages which researches are exploiting. These include increased efficacy, lower doses and less incidences of side effects. This is obtained through controlling the distribution of the drug through passive and active targeting to specific sites. Also, nanoengineering of these particles can ensure the formulation of effective carriers that may improve bioavailability and biocompatibility $[3,4]$.

With the global wave in nanotechnology in numerous applications, malaria treatment has not been left out. Research through different mechanisms on nanotechnologies for malaria treatment is on-going. Nanotechnology is being used in controlling the mosquito vector as well as killing the malaria parasite, as alternatives to conventional methods. For instance, the use of silver nanoparticles is gaining wide interest against mosquito-borne diseases. A study demonstrated the potency of a novel technique combining synthesize silver nanoparticles and the aqueous leaf extract of Bauhinia variegata, which resulted in a cheap, safe and environmentally friendly product [5]. A recent study developed nano-imitations (using polymer vesicles) of host cell membranes which was successful in deceiving and tricking malaria pathogens, thus proving useful as a potential approach towards developing novel vaccine strategies against malaria [6, 7]. In the study, it was revealed that these simple nanostructures could prevent invasion into host cells, thereby effectively interrupting the life cycle of the malaria pathogen.

Researchers are increasingly exploring the application of nanotechnology based systems to herbal actives for various therapeutic application. The main focus of this article is providing an evidence for exploring nanotechnologies for the effective therapy of malaria utilising phytomedicines. A review of the literature reporting plant-based medicines, their use and potential as nanotechnology systems was conducted on research databases. Relevant studies were identified through searches of online databases (including PubMed, Cochrane database, Google Scholar and Web of 
Science). Evidence to support the use and potential of nanophytomedicines for malaria is gaining significant interest and is reviewed here.

\section{CURRENT PHYTOMEDICAL MANAGEMENT OF MALARIA}

Antimalarial drug use and vector control are the most common approaches towards malaria control. Malaria, being an ancient disease, it is believed that early man might have resorted to the use of plant medicines in its management. Numerous locales are presently known to still wholly or partially rely on herbal medicines and the phytochemicals therein to abate symptoms and provide cure for the disease. They are suggested to be safer, have less adverse effect profiles, easier accessibility without the need for prescriptions and have better tolerability. Several plants have been reported as being effective and are used in the treatment of malaria. Current antimalarials derived from plants include artemisinin, and quinine. There are reports on the use of Anarcadium occidentalis (Anacardiaceae), Azadirachta indica (Meliaceae), Artemisia annua (Asteraceae), Cassia alata (Caesalpinioideae), Cinchona spp (Rubiaceae), Cochlospermum planchonii (Cochlospermaceae), Lippia multiflora (verbenacea), Khaya anthotheca (Meliaceae), Cryptolepis sanguinolenta (Apocynaceae), Myrtus communis (Myrtaceae), Phyllanthus amarus (Euphorbiaceae), Satureja thymbra (Lamiaceae), Thymus herba-barona (Lamiaceae) [8-10]. A main limitation of these plant-based medicines is the lack of/insufficient standardisation. Despite this, the evidence-based use of some of these phytomedicines in treating and managing malaria is widely reported $[2,8]$.

\subsection{ACTIVE PHYTOCHEMICALS IDENTIFIED FOR MALARIA THERAPY}

Several phytochemicals have been identified for their relevance in malaria therapy. A summary of this is illustrated in Table 1.

\subsubsection{Alkaloids}

Although generally bitter tasting, they are commonly used as phytomedicines and a plant may have different alkaloids. The highest concentrations of alkaloids are usually found in leaves, roots and barks. The root extract of Cryptolepis sanguinolentan containing the bioactive indoquinoline alkaloids is currently under clinical development for malaria treatment and is widely used in several African countries. These alkaloids have shown both in vitro and in vivo activity against Plasmodium falciparum including 
chloroquine-resistant strains [11, 12]. For instance, its herbal tea formulation has shown good clinical efficacy and safety in patients who had clinical features of uncomplicated malaria [12]. Another study examined the clinical efficacy of orally administered root decoction of Cochlospermum planchonii in comparison with chloroquine in the treatment of non-severe malaria [13]. Following treatment for five days, the study reported that $57 \%$ of chloroquine-treated and $52 \%$ of herbal-treated patients were cured, showing no detectable parasitemia, while at least $90 \%$ of all patients were asymptomatic. It has been reported that not only the alkaloids were active, but also saponins, tannins, phenolics, steroids, anthraquinones, which were present in the root decoction [14].

\subsubsection{Essential oils}

Volatile, aromatic essential oils obtained from plants have proven to be useful in the control of malaria $[15,16]$. They are environmentally friendly and are composed of bioactive compounds, hence their preference as suitable alternative mosquito larval control agents, and are potentially suitable for use in integrated pest management programs due to their safety and efficacy profile [17]. Dell'Agli et al investigated the anti-plasmodial effect of some plants used in the environmental control of the mosquito vectors of malaria. Myrtus communis, Satureja thymbra and Thymus herbabarona were examined following extraction of the essential oils using distillation techniques and chromatographic fractionation. The active components identified in these herbs included thymol, acylphloroglucinols (including myrtucommulone), which potently reduced parasitaemia in mice infected with $P$. berghei, with the essential oil of $S$. thymbra being the most active against $P$. falciparum [9].

\subsubsection{Polyphenols}

They are generally categorised into stilbenes, flavonoids, lignans and phenolic acids, based on the phenolic rings and the hydroxyl substitutions between these (Figure 1a). Numerous polyphenols have been reported to be active in the fight against malaria, including those obtained from Euphorbia hirta, Annona senegalensis, Steganotaenia araliacea, Zanthoxylum fagara, Khaya senegalensis, Phyllanthus muellerianus, Ficus exasperate, Hoslundia opposita, Xanthium brasilicum and Pupalia lappacea [18-20]. 


\subsubsection{Flavonoids}

Flavonoids (Figure 1b-e) are believed to exert these beneficial effects through their characteristic modulation of cell signalling pathways and antioxidant effects. Several flavonoids have been identified as being the bioactive moiety from phytomedicines used in combating malaria [21]. Artemisia annua and Artemisia indica from which the WHO recommended first line artemisinin-based combination therapy emanates is a classic example of a phytomedicine with the flavonoid responsible for its bioactivity $[22,23]$. Some of the flavonoids identified in Artemisia include; artemetin, quercimeritrin, chrysosplenol C, retusin, chrysosplenol D, eupatin, chrysosplenetine, apigenin, luteolin, acacetin, chrysoeriol and chrysin [23]. Clinical studies have proven that artemisinin and its derivatives are effective when used in malaria caused by $P$. vivax and $P$. falciparum, including uncomplicated and cerebral malaria [24-26].

\subsubsection{Tannins}

The antimalarial properties of tannins (Figure 1a) are widely reported. For instance, Punica granatum fruit rind are used as a traditional herb in malaria therapy, however, the fraction enriched in tannins showed greater activity against $P$. falciparum [27]. In a study, ellagitannins obtained from the fruit rind of Punica granatum (pomegranate) have shown potent antimalarial activity, in comparison to other phytochemicals obtained through an inhibition of the pro-inflammatory mechanisms involved in the onset of cerebral malaria [9, 28, 29]. Studies have revealed the antiplasmodial effect of several bioactives (including tannins) from Chromolaena odorata [30], Holoptelea integrifolia [31], Waltheria indica [32] and Horsfieldia spicata [33].

\subsubsection{Lignans}

There are reports on lignans Figure 1g) being exploited as lead compounds in new drug development, including antimalarial drug development [34, 35]. de Andrade-Neto et al reported the antiplasmodial effect of Aryltetralone Lignans extracted from Holostylis reniformis, where it was shown that these extracts were effective against Plasmodium berghei and a chloroquine-resistant strain of Plasmodium falciparum [36]. Another study reported that the tetrahydrofuran lignan- calopeptin 
from Nectandra megapotamica had shown in vitro antimalarial activity against Plasmodium falciparum [37]. Lignans isolated from Vernonia amygdalina, Pycnanthus angolensis, Hypericum lanceolatum, Glossocalyx brevipes, Asparagus africanus and Morus mesozygia have been reported to have antiplasmodial activity [21, 38, 39].

\subsubsection{Stilbenes}

Despite their benefits of antioxidative, anticarcinogenic and antiinflammatory properties, many stilbenes (Figure $1 \mathrm{~h}$ ) have been reported to possess antimalarial activity. For instance, a stilbene glycoside isolated from Parthenocissus tricuspidata has shown significant blood schizontocidal activity when tested in vivo against $P$. berghei, with mean survival time similar to that for chloroquine [40]. Mishra et al. have reported the inhibitory effect of piceatannol on protein tyrosine kinase at different growth stages of $P$. falciparum. Here it was shown that significant inhibition was observed in trophozoites and schizonts which may be due to the relevant role of protein tyrosine kinase in the initial asexual maturation of the plasmodium parasite [41]. Sharma et al. went further to show the antiplasmodial activity of novel stilbenechalcone hybrids, where the potency of some hybrids against chloroquine sensitive and resistant strains of $P$. falciparum were reported through different mechanisms including chromatin condensation, blocking the progression of the parasite life cycle at the ring or the trophozoite stages, DNA fragmentation and loss of parasitic mitochondrial membrane potential. This could be due to these hybrids causing apoptosis in malaria parasite [42].

\subsubsection{Glycosides}

Some glycosides (Figure $1 \mathrm{i}-\mathrm{m}$ ) have shown some in vitro and in vivo antimalarial efficacy. For instance, flavonol glycosides obtained from the extracts of Hydrangeae macrophylla and Euphorbia hirta (afzelin, quercitrin and myricitrin) showed $P$. falciparum inhibition at significantly low concentrations, without any signs of cytotoxicity $[43,44]$. The study also assessed the anti-malarial activity of other flavonol glycosides including, rutin, multinoside, isoquercitrin and quercitrin flavonols, which showed some antimalarial activity though not as potent as that from extracts of Hydrangeae macrophylla [43]. Cucurbitacin glycosides obtained from the traditional commonly used plant Datisca glomerata (including datiscoside and datiscoside B), 
have shown moderate in vitro antiplasmodial activity when the isolated compounds were compared against a chloroquine sensitive strain of $P$. falciparum [45].

\subsubsection{Terpenes and terpenoids}

Certain terpenes and terpenoids (Figure 1n) have been identified as being useful in malaria therapy. Some are being used as mosquito repellents, while others are parasiticidal. Rodrigues et al investigated some terpenes/terpenoids (farnesol, limonene, linalool and nerolidol) using cultures of the intraerythrocytic stages of the falciparum parasite. The study concluded that linalool, farnesol and nerolidol exhibited stronger inhibitory activity on the biosynthesis of the isoprenic side chain of the benzoquinone ring of ubiquinones in the schizont stage and combining these terpenes with other antimalarial drugs could be an approach to be exploited for malaria therapy [46]. Artemisinin, the first line antimalarial treatment base (derived from Artemisia annua) is a potent terpene believed to aid its malarial therapeutic response [47]. 
Table 1: Phytochemicals reported for their antimalarial effect

\begin{tabular}{|c|c|c|c|c|c|c|}
\hline Phytochemical & $\begin{array}{l}\text { Plants for } \\
\text { malaria }\end{array}$ & Family & $\begin{array}{l}\text { Specific } \\
\text { phytochemicals }\end{array}$ & $\begin{array}{l}\text { Plant part } \\
\text { extracted }\end{array}$ & Pharmacokinetic and safety data & Reference \\
\hline \multirow{5}{*}{ Alkaloids } & Cinchona spp. & Rubiaceae & $\begin{array}{l}\text { Modified } \\
\text { monoterpene- } \\
\text { derived alkaloids } \\
\text { (e.g. quinine, } \\
\text { quinidine, } \\
\text { cinchonidine, } \\
\text { cinchonine) }\end{array}$ & Bark & $\begin{array}{l}\text { Cinchona alkaloids have shown significant } \\
\text { cardiovascular effects and are administered } \\
\text { by rate-controlled infusions, due to the } \\
\text { potential of result of lethal hypotension. } \\
\text { Quinine monotherapy is the most widely } \\
\text { used treatment for malaria during the first } \\
\text { trimester of pregnancy. It is thought to be } \\
\text { safe in all trimesters of pregnancy }\end{array}$ & [48-50] \\
\hline & $\begin{array}{l}\text { Aspidosperma } \\
\text { spp (including } \\
\text { Aspidosperma } \\
\text { olivaceum) }\end{array}$ & Apocynaceae & $\begin{array}{l}\text { Monoterpenoid } \\
\text { indole alkaloids } \\
\text { (MIAs); } \\
\text { aspidoscarpine, } \\
\text { uleine, apparicine, } \\
\text { and N-methyl- } \\
\text { tetrahydrolivacine } \\
\text { Aspidospermine } \\
\text { Olivacine }\end{array}$ & $\begin{array}{l}\text { Bark } \\
\text { Leaves }\end{array}$ & $\begin{array}{l}\text { Extract fractions showed in vitro activity in at } \\
\text { low doses (IC } 50<5.0 \mu \mathrm{g} / \mathrm{mL} \text { ) using the anti- } \\
\text { HRPII test. Two fractions were toxic to } \\
\text { HepG2 cells }\end{array}$ & [51] \\
\hline & $\begin{array}{l}\text { Cryptolepis } \\
\text { sanguinolenta }\end{array}$ & Apocynaceae & $\begin{array}{l}\text { Indoquinoline } \\
\text { alkaloids }\end{array}$ & Roots & $\begin{array}{l}\text { An orally administered water extract of } \\
\text { Cryptolepis sanguinolenta has shown } \\
\text { efficacy comparable to chloroquine in a } \\
\text { clinical study. Using animal toxicity testing } \\
\text { data (from mice, rats and rabbits), its herbal } \\
\text { formulation appears safe }\end{array}$ & {$[11,12]$} \\
\hline & Cochlospermum & & & & & [13] \\
\hline & $\begin{array}{l}\text { spp. (including } \\
\text { Cochlospermum } \\
\text { planchonii and }\end{array}$ & Cochlospermaceae & & Roots & $\begin{array}{l}\text { The crude extract of Cochlospermum } \\
\text { tinctorium showed potent antiplasmodial } \\
\text { activity in mice, though fractions } \\
\text { demonstrated lower activity }\end{array}$ & [52] \\
\hline
\end{tabular}




\begin{tabular}{|c|c|c|c|c|c|c|}
\hline & $\begin{array}{l}\text { Cochlospermum } \\
\text { tinctorium) }\end{array}$ & & & & & \\
\hline Anthraquinones & $\begin{array}{l}\text { Pentas } \\
\text { micrantha }\end{array}$ & Rubiaceae & $\begin{array}{l}\text { 5,6-dihydroxylucidin- } \\
\text { 11-O-methyl ether }\end{array}$ & Roots & $\begin{array}{l}\text { Moderate antiplasmodial activity against } \\
\text { certain Plasmodium falciparum strains as } \\
\text { well as low cytotoxicity in MCF-7 cells }\end{array}$ & [53] \\
\hline Flavonoids & $\begin{array}{l}\text { Artemisia annua } \\
\text { Artemisia indica } \\
\text { Artemisia } \\
\text { absinthium } \\
\text { Artemisia dubia }\end{array}$ & Asteraceae & $\begin{array}{l}\text { Exiguaflavone A, } \\
\text { Exiguaflavone B, } \\
\text { Maackiain, } \\
\text { 2-(2, 4- } \\
\text { dihydroxyphenyl)- } \\
\text { 5,6-methylene } \\
\text { dioxybenzofuran } \\
\text { Eupatin, Casticin, } \\
\text { Chrysoplenetin, } \\
\text { Cirsilineol, } \\
\text { Chrysophenol-D, } \\
\text { Artemetin }\end{array}$ & $\begin{array}{l}\text { Leaves } \\
\text { Flowers } \\
\text { Roots } \\
\text { Stem }\end{array}$ & $\begin{array}{l}\text { Extracts and the volatile oil of Artemisia } \\
\text { indica demonstrated activity against malaria } \\
\text { parasites, malaria prophylactic effect } \\
\text { (through inhibition of recombinant plasmodial } \\
\text { fatty acid biosynthesis (PfFAS-II) enzymes. } \\
\text { They also showed low cytotoxicity against } \\
\text { mammalian cells }\end{array}$ & [54-56] \\
\hline \multirow[t]{2}{*}{ Glycosides } & $\begin{array}{l}\text { Stachytarpheta } \\
\text { cayennensis }\end{array}$ & Verbenaceae & $\begin{array}{l}\text { Phenylethanoid } \\
\text { glycosides }\end{array}$ & Leaves & $\begin{array}{l}\text { Glycosidic extracts demonstrated significant } \\
\text { blood schizonticidal activity in Albino Swiss } \\
\text { mice which was comparable to that of the } \\
\text { standard drug, chloroquine }\end{array}$ & {$[57,58]$} \\
\hline & $\begin{array}{l}\text { Hydrangea } \\
\text { macrophylla }\end{array}$ & Hydrangeaceae & Flavonol glycosides & Leaves & $\begin{array}{l}\text { There was significant proliferation inhibition } \\
\text { of Plasmodium falciparum at significantly low } \\
\text { concentrations with the absence of } \\
\text { cytotoxicity }\end{array}$ & [43] \\
\hline \multirow[t]{3}{*}{ Polyphenols } & $\begin{array}{l}\text { Sebastiania } \\
\text { chamaelea }\end{array}$ & Euphorbiaceae & Ellagic acid & \multirow[t]{3}{*}{$\begin{array}{l}\text { Leaves } \\
\text { Stem } \\
\text { Bark }\end{array}$} & $\begin{array}{l}\text { Studies have shown that } \\
\text { S. chamaelea extracts have no significant } \\
\text { cytotoxicity, significant antiplasmodial activity }\end{array}$ & \multirow[t]{3}{*}{$\begin{array}{l}{[18,28,59} \\
60]\end{array}$} \\
\hline & $\begin{array}{l}\text { Chrozophora } \\
\text { senegalensis }\end{array}$ & Euphorbiaceae & Ellagic acid & & $\begin{array}{l}\text { and portray strong synergy when co- } \\
\text { administered with chloroquine. Also, } \\
\text { C. senegalensis extracts have demonstrated }\end{array}$ & \\
\hline & $\begin{array}{l}\text { Anogeissus } \\
\text { leiocarpus }\end{array}$ & Combretaceae & $\begin{array}{l}\text { Ellagic acid } \\
\text { Gallic acid } \\
\text { Gentisic acid }\end{array}$ & & $\begin{array}{l}\text { significant antimalarial activity in a murine } \\
\text { malaria model }\end{array}$ & \\
\hline
\end{tabular}




\begin{tabular}{|c|c|c|c|c|c|}
\hline & $\begin{array}{l}\text { Phyllanthus spp } \\
\text { (including } P . \\
\text { muellerianus } \\
\text { and Phyllanthus } \\
\text { amarus) }\end{array}$ & Phyllanthaceae & Geraniin & & $\begin{array}{l}\text { Significant prophylactic and } \\
\text { chemotherapeutic antiplasmodial activity } \\
\text { (dose-dependent) has been demonstrated by } \\
\text { Phyllanthus amarus leaf extracts, } \\
\text { comparable to chloroquine. This was } \\
\text { assessed in } P \text {. Yoelli infected mice }\end{array}$ \\
\hline Saponins & $\begin{array}{l}\text { Quillaja } \\
\text { saponaria }\end{array}$ & Quillajaceae & $\begin{array}{l}\text { Quillaja saponins } \\
\text { including Quillaic } \\
\text { acid }\end{array}$ & Bark & $\begin{array}{l}\text { Extracts of Quillaja saponaria bark have } \\
\text { shown potent antimalarial activity and are in } \\
\text { being examined as a potential preventive } \\
\text { vaccine formulation, as a component of } \\
\text { RTS,S, a subunit malaria vaccine candidate }\end{array}$ \\
\hline $\begin{array}{l}\text { Stilbenes } \\
\text { /Lignins }\end{array}$ & Carissa edulis & Apocynaceae & Nortrachelogenin & $\begin{array}{l}\text { Root } \\
\text { Bark }\end{array}$ & [64] \\
\hline Terpenoids & Artemisia annua & Asteraceae & $\begin{array}{l}\text { Cadinane } \\
\text { sesquiterpenes } \\
\text { including artemisinic } \\
\text { acid, qinghao acid) } \\
\text { and artemisinin }\end{array}$ & $\begin{array}{l}\text { Seed } \\
\text { Leaves }\end{array}$ & $\begin{array}{l}\text { Semi synthetic artemisinin (and its } \\
\text { derivatives) in combination is currently the } \\
\text { favoured therapy against both drug-resistant } \\
\text { and cerebral malaria-causing strains of } \\
\text { Plasmodium falciparum, as it is active } \\
\text { against both the sexual and asexual stages } \\
\text { of the parasite cycle. Artemisinin is short- } \\
\text { acting with poor bioavailability }\end{array}$ \\
\hline
\end{tabular}




\section{LIMITATIONS AND CHALLENGES OF FORMULATING PHYTOMEDICINES}

Although tremendous progress has been made in the research of phytomedicines, there is still much to be done towards progressing these to industrial scale formulations. It is noteworthy that the major pharmaceutical companies have demonstrated renewed interest use of phytomedicines as lead compound and sources of new drugs [70]. Although several phytomedicines form the basis of several new drugs, their delivery may pose a challenge due to several reasons. Some drawbacks encountered in the formulation of phytomedicines include:

\subsection{Poor aqueous solubility}

For medicines administered through the oral route to exert their effects, they should be in solution in order to cross the barriers to absorption, as this influences their bioavailability. Several phytomedicines are known to exhibit low systemic availability [71]. For instance, artemisinin (the first line treatment for malaria) has poor aqueous solubility, being incompletely absorbed following oral administration. This is due to its poor dissolution attributes in gastrointestinal fluids [72]. This has led to some difficulty in formulating dosage forms as a result of variable dissolution rates and erratic bioavailability [73]. It has been reported that absorption of artemisinin could be modified by other constituents of Artemesia annua as a clinical pharmacokinetic study showed artemisinin formulated as a herbal tea was absorbed rapidly and with shorter Tmax in comparison its administration as capsules [74]. There are several reports on the application of nanotechnology in improving solubility, bioavailability and bioactivity of phytochemicals [75-79]. Besides the use of nanotechnology, this low solubility could be overcome through the use of solid dispersion of water-soluble carriers, prodrugs, self-emulsifying systems, complexation with $\beta$-cyclodextrin etc. [80, 81].

\subsection{Large molecular size}

Several constituents of phytomedicines show limited absorption. This may be as a result of the large molecular size of some of them, which hinders transport via passive diffusion. Some other have poor lipid solubility which serves as a barrier to crossing lipidic biological membranes, hence lower permeability [82]. These factors lead to low bioavailability of some phytomedicines. The formulation of phytosomes (achieved by 
linking phytoconstituents to phosphatidylcholine) and herbosomes provide better absorbed dosage forms with better pharmacokinetic profiles [83, 84].

\subsection{Standardization}

Standardisation of herbal medicines is a major limiting factor for their formulation and use as some are introduced into the market rigorous safety or toxicological evaluation, as their might be ineffective machinery to regulate manufacturing practices and quality standards in some countries [85]. The impact of environmental changes on the active ingredients influences the need to use pharmacological standardization to establish medicinal quality of the plants. In addition, insufficient scientific information about the acting pharmacological principles of the extracted phytocompounds (total extracts and isolated constituents) and the fact that the plants are not cultivated under controlled condition may partly be responsible for the failure to meet standardisation standards [86]. The differences in content, quantity and quality of some herbal products could be due to different extraction, processing and manufacturing methods utilised by manufacturers [87]. Also, there are reports on insufficient standardization and quality control of the herbal drugs used in clinical trials which may be due to different dosages of herbal medicines being used, improper randomization and use of insufficient number of patients, difficulty in establishing appropriate placebos (as a result organoleptic properties like taste and aroma) as well as variations in treatment durations [88]. All these factors make standardization difficult.

\subsection{Low yield}

Crude extracts of phytomedicines commonly contain several bioactives. The processes involved including appropriate plant identification, extraction processes, isolation of active constituents and fractionation process is time consuming. This, coupled with the low supply of the active ingredient supply eventually leads to low yield of the phytomedicines. This buttresses the need for advancement in combinatorial organic chemistry, discovery of semi-synthetic analogues as well as more sustainable extraction and purification techniques that may ensure higher yields [86]. A study demonstrated low yields of at least $0.16 \%$ for some lyophilized ethanol extract alkaloid fractionated from the antimalarial plant Himatanthus articulatus stem barks was fractionated by re-extraction under reflux yielding three fractions [89]. 


\subsection{Patient compliance and medication adherence}

It is well known that formulation and delivery methods could significantly influence the efficacy of a drug and inadvertently a phytomedicines. Many phytomedicines are presently available as teas, capsules, tablets, pressed juices, tinctures, solventextracted preparations or combinations of these various product forms. These are traditional delivery systems and are met with less patient acceptability which may negatively affect adherence [82]. Poor patient compliance is also due to large doses and sometimes less effectiveness reported with some available formulations [82]. An approach reported to result in better patient compliance is the formulation of liquid or solid self-emulsifying drug delivery systems. These are believed to lead to the formulations with enhanced solubility and bioavailability, better stability, more compact dosage forms, ease of handling/ portability; ultimately resulting in better patient compliance [90]. In addition, concerns over compliance with plant-based medicines varies according to local beliefs and socio-cultural status, and is less reliant on the efficacy of the traditional medicine [86]. This attitude is likely to lead to a negative bias towards users of these phytomedicines as some patients may continue with such treatment although it may show insufficient efficacy as a result of personal and community beliefs.

For these reasons, advanced drug delivery systems including nanotechnology-based systems provide several advantages that would be suitable for phytomedicines. These include, better targeting and more efficient delivery due to greater drug loading capacities, longer blood circulation times especially when linked to certain polymers, a decreased drug dose etc. 


\section{NANAOTECHNOLOGY INTERVENTIONS FOR OVERCOMING CHALLENGES OF PHYTOCHEMICAL ANTI-MALARIALS}

Current conventional drug treatment and delivery strategies for malaria are rife with several limitations. Table 2 illustrates the limitations of conventional drug delivery and how this can be overcome using nanotechnology based systems. The main concern with antimalarial drugs is their poor solubility, large dose, ability to damage healthy tissues, resulting in toxicity in addition to multidrug resistance by Plasmodium spp mediated by several factors including P-glycoprotein efflux transporters which have been resulted in poor uptake, low bioavailability and treatment failure. Advanced drug delivery systems and nanotechnology-based systems are steadily gaining increased interest in the management of malaria [91, 92]. Their better organ and tissue target ability, increased safety through decreased dosing requirements and reduced clearance makes them ideal for drug delivery, improving patients care.

These systems would be grouped into three main categories and discussed as polymer-based, lipidic systems as well as miscellaneous systems. 
Table 2: Limitations of conventional delivery systems and the merits provided by nanotechnology-based delivery systems

\begin{tabular}{|c|c|c|c|}
\hline Attribute & Conventional drug delivery systems & Nanotechnology-based drug delivery systems & References \\
\hline Size & $\begin{array}{l}\text { Larger size implies a smaller surface area, } \\
\text { which can result in the delivery of drugs to the } \\
\text { site of administration rather than the target site } \\
\text { because they are less easily bio-distributed. } \\
\text { Reduced intestinal uptake and clearance by } \\
\text { the mononuclear phagocyte system can occur } \\
\text { due to their larger size }\end{array}$ & $\begin{array}{l}\text { The nanocarriers are generally of approximately } 1-100 \mathrm{~nm} \text { in } \\
\text { size. This size is similar to most biological molecules and } \\
\text { structures so they can cross biological barriers, which } \\
\text { increases bio-distribution. Increased surface area to volume } \\
\text { ratio improves solubility and bioavailability. }\end{array}$ & [93] \\
\hline $\begin{array}{l}\text { Solubility and } \\
\text { bioavailability }\end{array}$ & $\begin{array}{l}\text { Cannot always increase the drugs aqueous } \\
\text { solubility so toxic excipients are sometimes } \\
\text { utilised. } \\
\text { The bioavailability is usually lower due to larger } \\
\text { size and poor solubility. This can result in } \\
\text { insufficient exposure and high inter-subject and } \\
\text { intra-subject variability. For this reason, the } \\
\text { intravenous route may be required }\end{array}$ & $\begin{array}{l}\text { Can provide hydrophilic and hydrophobic environments to } \\
\text { enhance solubility of poorly soluble drugs } \\
\text { This is more commonly associated with higher bio-availability } \\
\text { due to small size and improved aqueous solubility. }\end{array}$ & {$[94,95]$} \\
\hline Pharmacokinetics & $\begin{array}{l}\text { When given orally can have lower bioavailability } \\
\text { due to poor solubility of some APIs. They can } \\
\text { also undergo first pass metabolism and rapid } \\
\text { clearance from the body, further reducing their } \\
\text { bioavailability. When given intravenously, the } \\
\text { mononuclear phagocyte system can reduce } \\
\text { half-life. }\end{array}$ & $\begin{array}{l}\text { Can improve the bioavailability of drugs by improving their } \\
\text { solubility. Can also increase half-life by masking the drug } \\
\text { molecule and reducing its immunogenicity. }\end{array}$ & {$[96,97]$} \\
\hline Targeting & $\begin{array}{l}\text { Do not normally have target-specific recognition } \\
\text { moieties to target all cells. Therefore, higher } \\
\text { concentrations of the drug are required to } \\
\text { increase the drug concentration at the target } \\
\text { site. This could result in healthy tissue damage } \\
\text { and side effects. }\end{array}$ & $\begin{array}{l}\text { Active targeting using target-specific recognition moieties such } \\
\text { as a small peptide, antibody or protein. This improves the } \\
\text { drug's efficacy and therapeutic index. Side effects and damage } \\
\text { to healthy tissue is reduced so patient tolerability and } \\
\text { compliance is improved. }\end{array}$ & {$[98,99]$} \\
\hline
\end{tabular}


Stimuli-responsive

These are not normally formulated to respond

to stimuli such as enzymes or $\mathrm{pH}$.

Efficacy

Comparable lower efficacy due to lower

concentration of drug reaching the active site.
Could be responsive to $\mathrm{pH}$, enzymes or other stimuli. Some

nanotechnology-based systems are formulated so they release

the drug molecules at certain $\mathrm{pH}$, which increases drug

concentration at the desired site.

Higher efficacy due to improved bioavailability, targeting,

reduced degradation and clearance.
[100]

$[101,102]$

[101, 102] 


\subsection{Polymer-based delivery systems for antimalarial phytochemicals}

Dendrimers, polymeric micelles, polymeric nanoparticles and polymer-drug conjugates are some of the polymer-based nanotechnology systems commonly investigated and utilised for drug delivery. Several synthetic and natural polymers have been used in the formulation of nanotechnology systems including; polyesters, polyurethanes, polyanhydrides, polyoxolates, polydioxanones, chitosan, dextran, starch, heparin, gelatin etc [103-105]. In many instances, these polymers possess unique properties and are suitable for drug delivery, with the requirement that they should be biocompatible. This property of polymer biocompatibility often is associated with a biodegradable attribute of the polymer [103]. It has been shown that some of these polymers can increase the size of drug molecules, which helps to reduce renal clearance. They also have been reported to increase solubility and reduce immunogenicity by masking the drug molecule [106]. These polymeric nanocarriers synthesised from natural and synthetic monomer subunits, are one the most frequently investigated carrier system, where drugs can be conjugated covalently or incorporated via hydrophobic interactions $[107,108]$. Antimalarial phytomedicines could either be conjugated onto the surface of these nanosystems or physically encapsulated within their structure, according to their preparation method.

\subsubsection{Dendrimers}

Dendrimers are composed of mono-dispersed, highly branched polymeric complexes (Figure 2a), which are produced by either convergent or divergent methods. As a result of their narrow polydispersity indices, uniform products are more easily manufactured [109]. Although dendrimers are of varying types, polypropyleneimine (PPI) and polyamidoamine (PAMAM) are commercially available and most commonly investigated [110, 111]. They are delivery systems for anionic, cationic, hydrophilic and hydrophobic drugs because full generation PAMAM dendrimers have terminal amino groups and half-generation dendrimers have carboxylate and ester groups [112]. PAMAM dendrimers have been investigated as a malaria vaccine delivery option. This was studied through an in silico computational model investigating and eight-branching unit which could be formed through combinations of epitopes obtained from the whole sequenced genome of $P$. falciparum [113]. PEG-lysine type dendritic peptide-based nanoparticulate carriers have been reported for sustained and 
controlled delivery of artemether through intravenous route of administration. PEGamine was taken as core in the present system and various generations of dendritic nanoparticles were synthesized by fluorenyl methoxy carbonyl (FMOC)-based liquid phase peptide synthesis process. The systems were further conjugated with chondroitin sulphate [114]. In another study polymeric amphiphilic micellar system has been reported for solubilsation of artemether whereby methoxy polyethylene glycol (MPEG) 2000 and 5000 were used as hydrophilic terminal [115].

\subsubsection{Polymeric micelles}

Polymeric micelles (Figure 2b) consist of amphiphilic copolymers which self-assemble, into spherical mono-layered structures in aqueous environment. Two discrete regions exist, a hydrophilic shell which encapsulates a hydrophobic core where poorly soluble drugs may be incorporated [116]. Poly(L-amino acid)s and poly(ester)s are common hydrophobic copolymers used for polymeric micelle formation. They are preferred for delivering hydrophobic drugs, improving their aqueous solubility and thus enhance oral bioavailability, so are well suited for several phytochemicals [117]. These polymeric micelles have also showed narrow polydispersity, enhanced stability and have small sizes of between 10-200nm [118], making them less likely to be phagocytosed and cleared from the blood. Furthermore, reduced drug leakage is likely to occur with polymeric micelles compared to liposomes [119], making these carrier systems more stable as formulations. Polymeric micelles, however, have higher toxicity when compared to the lipid based formulations due to the attributes of some polymeric materials [120]. Phytomedicine-loaded polymeric nanomedicines use been reported $[91,121]$.

Curcumin (a diarylheptanoid isolated form Curcuma longa) is well known for its antimalarial potency [122 123]. However, limiting factors such as its extremely low oral bioavailability hampers its application as therapeutic agent. Curcumin-loaded-4-Arm Poly(Ethylene Glycol)-Block-Poly(Anhydride-Esters) micelles prepared by a solid dispersion method have been reported with hydrodynamic diameter of $151.9 \mathrm{~nm}$ and the drug loading content of 7.0\% and encapsulation efficiency 85.2\%. Curcumin encapsulated within 4arm PEG-b-PAE micelles was amorphous and followed biphasic drug release pattern with rapid release at the initial stage and slow release later [124]. As polymeric micelles have been advocated as efficient drug delivery approach for multiple and combination 
therapeutics it might prove useful for artemisinin-based combination, the first line malaria treatment [125].

\subsubsection{Polymer-drug conjugates}

Polymer-drug conjugates are a widely used delivery system which has shown great potential in the delivery of therapeutic properties of proteins and small molecules. They offer significant benefits when compared to conventional drug delivery systems in terms of prolonged half-life, improved stability, enhanced aqueous solubility, reduced immune response and also specific targeting to tissues or cells [126]. Some of these properties could be improved following conjugation to water soluble polymers. Commonly utilised polymers include $\mathrm{N}$-(2-hydroxypropyl) methacrylamide copolymer (HPMA), polyglutamic acid (PGA), polyvinylpyrrolidone (PVP) and poly (ethylene glycol) (PEG), while newer ones are routinely investigated and proposed [126].

There are some studies exploiting polymer drug conjugates for malaria therapy. For instance a recent study by Kumar et al [127] demonstrated a delivery approach for radical cure of malaria utilising different polymer-drug conjugates with conventional antimalarials; primaquine and dihydroartemisinin in conjugation with either 2-propoxy substituted polyphosphazenes, 4-acetamidophenoxy substituted polyphosphazenes, 4-formyl substituted polyphosphazenes and 4-aminoethylbenzoate substituted polyphosphazenes. The study concluded that the formulations showed promising antimalarial efficacy at lower doses in comparison to the standard drug combination, without any recrudescence over 5 weeks, suggesting its potent efficacy against resistant malaria [127].

In another study, Yang et al investigated the use of biodegradable polymer-curcumin conjugate micelles with a view to enhance its drug loading and improve its delivery. In the study, a hydrophobic block containing poly (lactic acid) was utilised as the polymer with the use of tris (hydroxymethyl) aminomethane linker which was conjugated to multiple curcumin molecules while the hydrophilic block was methoxy-poly(ethylene glycol) (mPEG) [128]. This approach could be exploited in the delivery of curcumin as a nanophytomedicine.

\subsection{Lipid-based delivery systems}

Lipid-based carriers composed of natural and synthetic lipids have proved an attractive research area, with good biocompatibility, biodegradability and cell permeability. They 
include liposomes, lipid nanoparticles and nanoemulsions. Their hydrophobicity enables them to cross the phospholipid bilayer of cells to increase permeability. However, the use of excipients to improve stability and kinetics can increase their toxic potential, which is still limited when compared to most polymeric based systems. Antimalarial drugs can be solubilised or encapsulated within the oil/lipids causing enhanced bioavailability. Both liposomes and solid lipid nanoparticles have been shown to cross the blood brain barrier and therefore could be useful drug strategy for cerebral malaria [129, 130]. Certain lipid liposomes have been used as adjuvants for vaccines for malaria, where they have shown the ability of simultaneously activating the major histocompatibility complex class I and II pathways and inducing antibody and cellular immune responses [31].

\subsubsection{Liposomes}

Liposomes are spherical amphiphilic phospholipids which self-assemble into bilayers encapsulating an aqueous core made up of a phospholipid bilayer (Figure 2c). This biphasic characteristic allows the encapsulation of both hydrophobic and hydrophillic drugs. They have been most successful in gaining FDA (the Food and Drug Administration) approval, after the first liposome formulation Doxil ${ }^{\circledR}$ (Doxorubicin) have been reported to improve efficacy and minimise drug toxicity. Besides the ability to be formulated for controlled release, they have relatively longer circulation time, permitting sufficient accumulation at the parasitic site. PEGylation can increase bioavailability of liposomal drugs as opsonisation by macrophages is prevented, reducing the clearance rate [132]. PEG is a water soluble, generally non-toxic and non-immunogenic surface modifier, which is used to prolong circulation time because PEG chains are hydrated and flexible so they interact less with plasma proteins and cells surfaces. Liposomal targeting could also be enhanced by attaching ligands, such as antibodies on the surface which are specific to a receptor on the target cell. Generally, liposomes have the advantage of providing good entrapment of hydrophobic compounds and easy preparation. Stability is sometimes a concern which may be addressed by lyophilisation, although this process can rupture the lamellar phase resulting in leakage of the encapsulated drug. A potential drawback of conjugated liposomes is their relatively large size, which causes them to usually be recognised as foreign and removed via the mononuclear phagocytic system [133]. 
Artemisinin and its derivatives (including dihydroartemisnin) form WHOs first line treatment of malaria, though they are being now investigated for their anticancer properties. A study investigated liposome as formulation strategy towards obtaining effective delivery of dihydroartemisinin (DHA) Because of its poor water solubility, low bioavailability and low half-life (34-90 $\mathrm{min}$ ), there is urgent need for development of improvised formulation of DHA. The formulation properties were assessed in terms of size and morphology, zeta-potential, polydispersity index, physical and chemical stabilities and encapsulation efficiency [134]. Curcuminoids are polyphenols derived from the root of Curcuma longa, which have shown potential in managing malaria. Aditya et al. explored the potential of liposomes for the intravenous delivery of curcuminoids using a mouse model, where curcuminoids-loaded liposomes alone and in combination with $\alpha / \beta$ arteether were evaluated in Plasmodium berghei infected mice. The study concluded that the curcuminoids-loaded liposomes showed promising and improved antimalarial activity [135].

In another study four liposomal formulations were investigated viz. Artemisinin-loaded conventional liposomes (A-CL), artemisinin-curcumin-loaded conventional liposomes (AC-CL), artemisinin loaded PEGylated liposomes (A-PL) and artemisinin-curcuminloaded PEGylated liposomes (AC-PL) prepared using film hydration method. The artemisinin-loaded PEGylated liposomes showed strongest antiplasmodial activity when tested in P. berghei NK-65- infected mice. All the liposomal treatments extended the period of survival of the mice until 30 days post-inoculation as compared to negative control group which died 12 days post inoculation, showing 40\% increased parasitaemia levels. During the course of treatment, reduction in parasitaemia was faster in mice infected with $P$. berghei and treated with AC-PL, which reduced the parasitaemia to about $60 \%$ of the initial value after only 3 days. In all liposomal treatments, parasitaemia was reduced more than $93 \%$ of the initial value starting from day 5 . The infection was almost totally reverted in mice treated with $A-C L$ after 7 days and with $A C-C L, A-P L$ and AC-PL after 5 days thus proving the potential of liposomes in delivery of antimalarial phytochemicals (136).

\subsubsection{Lipid nanoparticles}

Solid lipid nanoparticles (SLNs), illustrated in Figure $2 \mathrm{~d}$ are colloidal carriers which are formulated using lipids that are solid at room temperature. They are easily prepared via high pressure homogenization, ultrasonication and microemulsion template 
techniques, allowing for high scale production. Hydrophobic compounds are easily encapsulated into the solid lipid core, leading to an increased stability, reduced degradation, sustained and prolonged release. Formulating drugs as SLNs has also been reported to result in decreased toxicity and enhanced target specificity of drugs. These SLNs are usually formulated with solid lipids, surfactants and water, with the lipids usually of relatively high melting points $[137,138]$. Similar to liposomes, they are well suited for the delivery of hydrophobic drugs, but are reported to have improved stability, especially when coated with polymers like polyethylene glycol (PEG) [137]. PEG, a versatile surface agent capable of increasing aqueous and lipid solubility, also confers good permeability across biological membranes [138]. However, some formulations with SLNs have also shown enhanced clearance by the reticuloendothelium system [139, 140]. Gupta et al have investigated delivery of quinine to the brain as transferrin-conjugated solid lipid nanoparticles. Quinine is widely used in the management of cerebral malaria and this effect was investigated in albino rats, where it was concluded that there was an enhanced uptake in brain tissue when the transferrin conjugated SLN was compared with unconjugated SLNs. In addition, plasma drug concentrations observed were higher than following SLN administration in comparison with the conventional intravenous dose [141].

Curcumin, despite its great potential to be developed as a drug, is limited by its low aqueous solubility, poor stability and low bioavailability following oral administration [142]. Curcumin loaded lipid nanocarrier have been reported to be very effective approach for enhancing the oral absorption of poorly water-soluble curcumin and have great potential for future clinical application [143,144. Memvanga et al. formulated a lipid-based drug delivery system with curcumin which was reported to have a high drug loading capacity, high aqueous solubility and enhanced cell permeability. Its antimalarial efficacy was enhanced as well as a significant delay in recrudescence in Plasmodium berghei-infected mice was observed when the curcumin-lipid based drug delivery system was combined with a sub-therapeutic dose of $\beta$-arteether [145]. This is suggestive of a promising approach for the treatment of malaria, where an artemisinin-based combination therapy produces better therapeutic outcomes $[146,147]$.

Nayak et al demonstrated the use of lipid nanoparticles for the delivery of curcuminoids for parenteral administration. For the production of nanoparticles, trimyristin, tristerin 
and glyceryl monostearate were selected as solid lipids and medium chain triglyceride (MCT) as liquid lipid. In vivo pharmacodynamic activity revealed 2-fold increase in antimalarial activity of curcuminoids entrapped in lipid nanoparticles when compared to free curcuminoids [148].

Nanostructured lipid carriers (NLCs) are lipid nanocarriers formulated using biocompatible solid lipid and liquid lipids (oil). The aqueous nature of NLC, their nanostructure and the biocompatibility of the excipients enables intravenous delivery of the therapeutic agents using this nanocarrier [149]. Also NLCs provide sustained delivery thus maintaining drug levels for prolonged period of time which is helpful in combating recrudescence commonly associated with antimalarial drugs. Joshi et al, have reported nanostructured lipid carriers (NLC) for the intravenous delivery of artemether (ARM) employing microemulsion template technique $(63 \pm 28 \mathrm{~nm})$, encapsulation efficiency ( $30 \pm 2 \%)$ and sustained release up to $24 \mathrm{~h}$. ARM-NLC had lower haemolytic potential $(\sim 13 \%)$ as compared to all the formulation components when studied individually. In vivo studies clearly demonstrated that ARM-NLC was significantly more effective as compared to the marketed formulation (Larither®) indicating the advantage of NLC. ARM-NLC showed quick onset of action ( $95 \%$ antimalarial activity) as compared to marketed injection ( $45 \%$ antimalarial activity) and demonstrated antimalarial activity for a longer duration indicating that ARM-NLC may be long circulating in-vivo and that entrapped ARM may be released in a sustained manner. ARM-NLC showed significantly higher survival rate after 31 days as compared to marketed formulation, which showed no survival proving the advantage of the NLC system over the marketed oily intramuscular formulation $\left(\right.$ Larither $\left.^{\circledR}\right)[150]$.

Chinaeke et al examined the in vitro-in vivo correlation of wax-soybean oil-based artesunate-loaded lipospheres. It was revealed that the formulated lipospheres had maximum encapsulation efficiency of $80 \%$, with a bioavailability enhancement factor of 2.108 when compared with tablets [151]. These studies show the potential of improved efficacy if phytochemicals are formulated as nanolipid systems. 


\subsubsection{Nanoemulsion}

Lipid nanosized emulsions or nanoemulsions (NE) are dispersions of nanosized oil droplets which are immiscible in the stationary continuous phase, synthesised from bio-acceptable components, capable of integrating hydrophobic drug in the nanorange, yielding greater surface area [152].

Arteether nanoemulsion (ARTE-NE) has been reported as oral delivery system for arteether (ARTE) for improving its solubility and bioavailability. The pharmacokinetic study showed significantly enhanced bioavailability of ARTE in ARTE-NE. The ARTENE showed significantly high antimalarial efficacy and survival rate of mice giving $80 \%$ cure rate at $12.5 \mathrm{mg} / \mathrm{kg}$ for 5 days in comparison to $30 \%$ cure rate of ARTE in groundnut oil at the same daily dose and it was also comparable to the $100 \%$ cure rate at $12.5 \mathrm{mg} / \mathrm{kg}$ for 5 days for ART given intramuscularly [153].

Microemulsion preconcentrate for artemether ( $\sim 183 \mathrm{~nm}$, PDI 0.498) exhibited 2.6-fold higher antimalarial activity than the marketed formulation Larither ${ }^{\circledR}$. Nanosize of the microemulsion, instantaneous dissolution of the drug, quick absorption, enhancement in bioavailability, protection of from acidic microenvironment of stomach and antimalarial effect of the excipients have been listed as possible attributes responsible for higher activity [154].

\subsection{Miscellaneous nanotechnology-based drug delivery systems}

Some nanotechnology-based drug delivery systems that do not fit into the broad categories of polymer or lipid-based systems, and would be discussed as miscellaneous systems. These include metallic nanoparticles, carbon nanotubes, nanosuspensions etc.

\subsubsection{Carbon nanotubes}

Carbon nanotubes (CNT) are drug delivery systems made of graphite and constructed in cylindrical tubes, which are able of adsorbing or linking to several therapeutic and diagnostic agents [155-157] (Figure 2e). Single-walled CNT and multi-walled CNT are the main types, which are imaginatively produced by rolling up a single layer of graphene sheet or by rolling up many layers to form concentric cylinders [158, 159]. They have good attributes, as a result of their nanosize and minute mass, strong mechanical potency, coupled with high electrical and thermal conductivity [160]. 
Despite their potential for medical and pharmaceutical applications, many CNT are insoluble in all solvents, generating health concerns related to their toxicity [161, 162]. They are considered as an immunization strategy for antigen delivery against infectious diseases and show promise for future malaria vaccine application [163]. It is thought that if antigens are encapsulated within CNTs, they could be more protected from external factors and maintains their correct conformation, further enhancing their immunization potential [164, 165].

A study reported the use of an immunosensor using antibody raised against HRP II for detecting Plasmodium falciparum. Here, disposable screen-printed electrodes were modified with multiwall carbon nanotubes and gold nanoparticles which demonstrated significantly high levels of detection, explaining its use as a potential biomarker for fast and reliable malaria detection [166]. The potential of CNTs in the delivery of artemisinin and its derivatives for malaria have also been investigated [167]. There is paucity of information on the use of CNT as a drug delivery method for malaria phytomedicines, although they have demonstrated some promise.

\subsubsection{Metallic nanoparticles}

Metal and magnetic nanoparticles (including those of aluminium, silicon, iron, cadmium, selenium, gold, indium, calcium and silver) have gained significant interest in recent years [168]. Their chemical functional groups are usually modified, allowing their conjugation with therapeutic proteins, ligands and organic/inorganic molecules for several applications. They find application in diagnostic imaging, as means for targeted drug delivery and vehicles for gene therapy [169, 170]. Auranofin (AF) is an effective gold compound used for the treatment of malaria. The combination of artemisinin and AF has showed synergistic antimalarial effects [171] Streptomyces spp LK-3 (JF710608) mediated gold nanoparticles (Au-N-LK3) have been prepared by inoculation of Streptomyces spp LK-3 (JF71060) into $100 \mathrm{ml}$ of broth (50\% sea water) and incubated in rotary shaker incubator at $28^{\circ} \mathrm{C}$ for 7 days. Chloroauric acid aqueous solution was added mixture was kept in shaker at $28^{\circ} \mathrm{C}$ at $120 \mathrm{rpm}$ for $24 \mathrm{hrs}$ to obtain gold nanoparticles $(5-50 \mathrm{~nm})$. Au-N-LK3 treatment in Plasmodium berghei ANKA ( $\mathrm{PbA}$ ) infected mice delayed the parasitemia rise ( $6 \%)$ compared to $\mathrm{PbA}$ infection on 8 days post infection. Survivability of mice increased to $\sim 85 \%$ in Au-N-LK3 treated mice in contrast to in $\mathrm{PbA}(\sim 50 \%)$ infected mice, 8 day post infection with respect to control. No histological changes were observed in in spleen and liver tissue and 
confirmed up-regulation of TGF- $\beta$ and down-regulation of TNF- $\alpha$ in tissue and serum levels in Au-N-LK3 treated mice [172]Al-Deen et al have reported the use of superparamagnetic iron oxide nanoparticles to facilitate delivery of a malaria DNA vaccine into eukaryotic cells, where the application of an external magnetic field significantly enhanced transfection efficiency [173].

\subsubsection{Nanosuspensions}

Nanosuspensions involve a nanosized drug being suspended in either an aqueous or oily medium. They are advantageous over some other drug delivery systems as the drug itself is nanosized and suspended, rather than being encapsulated/conjugated within a carrier, thus ensuring 100\% drug loading and encapsulation efficiency. In comparison, nanosuspensions are relatively simple systems composed of drug nanoparticles and surfactants required for dispersion, formulated for a range of routes. Being crystalline nanosized drug particles, their small size increases their surface area, allowing for greater dissolution rate and improves the bioavailability of hydrophobic drugs [174].This approach has been reported for dihydroartemisinin (DHF) whereby DHF nanosuspension with mean particle size of 80-220 nm showed higher activity on $P$. falciparum $\mathrm{K} 1$ strain [175]. In another study, nanotized curcumin was reported to be non-toxic, with a narrow poly dispersity index and improved aqueous dispersibility. The formulation further demonstrated very significant growth inhibition of Plasmodium falciparum and Plasmodium berghei-infected mice [176]. These systems show great potential for the delivery of insoluble malaria nanophytomedicines.

\subsubsection{Pheroids}

Pheroid technology is a patented colloidal delivery system consisting of a dispersed phase of plant based essential fatty acid in a nitrous oxide saturated continuous water phase. It consists of a lipid bilayer that is dynamic and constantly changing, with high stability and ability to entrap both hydrophilic and lipophilic drugs. The structure and size of Pheroid system can be manipulated for various applications [177]. Pheroid vesicle formulations of Artemisone - novel artemisinin derivative with good antimalarial activity but poor and erratic absorption and low bioavailability, have been prepared by heating and mixing vitamin $F$ ethyl ester, Cremaphor ${ }^{\circledR} E L$ and tocopherol along with PEG 400 and BHA to form the oil phase. The drug was added to oil-phase at room temperature and agitated to dissolve drug particles. The nitrous oxide water was then 
added to the oil-phase (1:9 v/v). The mixture was homogenised at $8000 \mathrm{rpm}$ for $1 \mathrm{~min}$. Pharmacokinetic behaviour of the developed formulation showed that the Tmax of artemisone, when incorporated in the Pheroid vesicle formulation, was delayed by a time-factor of 4 in comparison to that of the reference formulation. The Cmax for reference formulation produced a Cmax of $809.5 \mathrm{ng} / \mathrm{ml}$ while the Pheroid vesicle formulation gave a Cmax of $1550.0 \mathrm{ng} / \mathrm{ml}$. The reference formulation had a $t_{1 / 2}$ of approximately 20 min while the Pheroid vesicle formulation extended the $t_{1 / 2}$ to more than $60 \mathrm{~min}$. The Pheroid formulation was absorbed 4.57 times better than the reference formulation [178].

\section{Conclusions and Future Perspectives}

This review article highlights some nanoparticulate systems which are being modified for their potential applications in the treatment of malaria. Nanotechnology-based systems are developing to produce feasible, practical formulations, more thought to emerge in the next few years, with improved pharmacokinetic profiles, lower incidences of recrudescence and improved bioavailability. Despite their demonstrated successes; numerous challenges remain before some of these nanophytomedicines systems especially regarding standardisation, safety, stability, costs and drug loading. For instance, with respect to their toxicity, some of their components could cause immunotoxicity when they act as antigens. In addition, as a result of the relatively low encapsulation efficiency and loading capacity of some of these drug delivery systems, higher amounts of excipients used in their formulation could lead to other toxicities. Future research would need to address these issues and assess performance in humans (as most studies conducted in cell lines and animal in vivo models may not translate to humans). This presents significant challenges in ensuring that these become clinically viable therapies. The design and testing of novel methods of controlling the interaction of nanomaterials with the body are some of the current barriers to translating these technologies to therapies. Furthermore, it seems reversible PEGylation and versatile excipients such as d-a-tocopheryl polyethylene glycol 1000 succinate hold much promise in establishing nanophytomedicines as a reality. Although the development of phytomedicines-based nanotechnology drug delivery systems is still emerging, it shows a promising future. 


\section{Figure legends}

Figure 1: Chemical structures of (a) polyphenols (b) flavone (c) flavonol (d) flavanone (e) flavanonol (f) gallic acid (g) dibenzylbutane skeleton, the base structure for several lignans (h) base structure of stilbenes (i) anthraquinones (j) coumarins ( $k$ ) cyanogenic glycosides (l) steroid structure base for saponin glycosides $(m)$ steviol $(n)$ isoprene structure, the base for terpenoids

Figure 2: Illustration of nanotechnology-based delivery systems (a) poly(amido)amine (PAMAM) dendrimer (b) polymeric micelle (c) liposomes (d) solid lipid nanoparticle (e) carbon nanotube

\section{Table legends}

Table 1: $\quad$ Phytochemicals reported for their antimalarial effect

Table 2: $\quad$ Limitations of conventional delivery systems and the merits provided by nanotechnology-based delivery systems 


\section{References}

1. Oga EF, Sekine S, Shitara Y, Horie T. Pharmacokinetic Herb-Drug Interactions: Insight into Mechanisms and Consequences. Eur J Drug Metab Pharmacokinet, 2015.

2. Willcox ML, Bodeker G. Traditional herbal medicines for malaria. BMJ, 2004; 329: 1156-9.

3. McNeil SE. Unique benefits of nanotechnology to drug delivery and diagnostics. Methods Mol Biol, 2011; 697: 3-8.

4. Pathak K, Raghuvanshi S. Oral bioavailability: issues and solutions via nanoformulations. Clin Pharmacokinet, 2015; 54: 325-57.

5. Govindarajan M, Rajeswary M, Veerakumar K, Muthukumaran U, Hoti SL, Mehlhorn $\mathrm{H}$, Barnard DR, Benelli G. Novel synthesis of silver nanoparticles using Bauhinia variegata: a recent eco-friendly approach for mosquito control. Parasitol Res, 2015.

6. Najer A, Wu D, Bieri A, Brand F, Palivan CG, Beck HP, Meier W. Nanomimics of host cell membranes block invasion and expose invasive malaria parasites. ACS Nano, 2014; 8: 12560-71.

7. Najer A, Thamboo S, Duskey JT, Palivan CJ, Beck H-P, Meier W. Analysis of Molecular Parameters Determining the Antimalarial Activity of Polymer-Based Nanomimics. Macromolecular Rapid Communications, 2015; 36: 1923-1928.

8. Willcox M. Improved traditional phytomedicines in current use for the clinical treatment of malaria. Planta Med, 2011; 77: 662-71.

9. Dell'Agli M, Sanna C, Rubiolo P, Basilico N, Colombo E, Scaltrito MM, Ndiath MO, Maccarone L, Taramelli D, Bicchi C, Ballero M, Bosisio E. Anti-plasmodial and insecticidal activities of the essential oils of aromatic plants growing in the Mediterranean area. Malar J, 2012; 11: 219.

10. Raza A, Shujatullah F, Khan HMS, M.Malik, A. Malaria and Phytomedicine. Springer Netherlands 2013.

11. Bugyei KA, Boye GL, Addy ME. Clinical efficacy of a tea-bag formulation of cryptolepis sanguinolenta root in the treatment of acute uncomplicated falciparum malaria. Ghana Med J, 2010; 44: 3-9.

12. Tempesta MS. The clinical efficacy of cryptolepis sanguinolenta in the treatment of malaria. Ghana Med J, 2010; 44: 1-2.

13. Benoit-Vical F, Valentin A, Da B, Dakuyo Z, Descamps L, Mallié M. N'Dribala (Cochlospermum planchonii) versus chloroquine for treatment of uncomplicated Plasmodium falciparum malaria. J Ethnopharmacol, 2003; 89: 111-4.

14. Nafiu MO, Akanji MA, Yakubu MT. Toxicity of aqueous root extract of Cochlospermum planchonii (an anti-malarial herb) in selected tissues of mice. Comparative Clinical Pathology, 2013; 22: 1211-1218.

15. Xue RD. Introduction to symposium on mosquitoes and plants. J Am Mosq Control Assoc, 2008; 24: 134-7.

16. Amer A, Mehlhorn $\mathrm{H}$. Repellency effect of forty-one essential oils against Aedes, Anopheles, and Culex mosquitoes. Parasitol Res, 2006; 99: 478-90.

17. Cheng SS, Huang CG, Chen WJ, Kuo YH, Chang ST. Larvicidal activity of tectoquinone isolated from red heartwood-type Cryptomeria japonica against two mosquito species. Bioresour Technol, 2008; 99: 3617-22.

18. Ndjonka D, Bergmann B, Agyare C, Zimbres FM, Lüersen K, Hensel A, Wrenger C, Liebau E. In vitro activity of extracts and isolated polyphenols from West African medicinal plants against Plasmodium falciparum. Parasitol Res, 2012; 111: 827-34.

19. Nour AM, Khalid SA, Kaiser M, Brun R, Abdallah WE, Schmidt TJ. The antiprotozoal activity of sixteen asteraceae species native to Sudan and bioactivity-guided isolation of xanthanolides from Xanthium brasilicum. Planta Med, 2009; 75: 1363-8.

20. Achenbach $\mathrm{H}$, Waibel $\mathrm{R}$, Mayunga $\mathrm{HHN}$, Weenen $\mathrm{H}$. Antimalarial compounds from Hoslunda opposita. Phytochemistry, 1992; 31: 3781-3784. 
21. Ntie-Kang F, Onguéné PA, Lifongo LL, Ndom JC, Sippl W, Mbaze LM. The potential of anti-malarial compounds derived from African medicinal plants, part II: a pharmacological evaluation of non-alkaloids and non-terpenoids. Malar J, 2014; 13: 81.

22. Pohlit AM, Lima RB, Frausin G, Silva LF, Lopes SC, Moraes CB, Cravo P, Lacerda MV, Siqueira AM, Freitas-Junior LH, Costa FT. Amazonian plant natural products: perspectives for discovery of new antimalarial drug leads. Molecules, 2013; 18: 921940.

23. Ferreira JF, Luthria DL, Sasaki T, Heyerick A. Flavonoids from Artemisia annua L. as antioxidants and their potential synergism with artemisinin against malaria and cancer. Molecules, 2010; 15: 3135-70.

24. Yarnell E. Artemisia annua (Sweet Annie), Other Artemisia Species, Artemisinin, Artemisinin Derivatives, and Malaria. Journal of Restorative Medicine, 2014; 3: 6984.

25. Mclntosh HM, Olliaro P. Artemisinin derivatives for treating uncomplicated malaria. Cochrane Database Syst Rev, 2000: CD000256.

26. McIntosh HM, Olliaro P. Treatment of severe malaria with artemisinin derivatives. A systematic review of randomised controlled trials. Med Trop (Mars), 1998; 58: 61-2.

27. Dell'Agli M, Galli GV, Corbett Y, Taramelli D, Lucantoni L, Habluetzel A, Maschi O, Caruso D, Giavarini F, Romeo S, Bhattacharya D, Bosisio E. Antiplasmodial activity of Punica granatum L. fruit rind. J Ethnopharmacol, 2009; 125: 279-85.

28. Soh PN, Witkowski B, Olagnier D, Nicolau ML, Garcia-Alvarez MC, Berry A, BenoitVical $F$. In vitro and in vivo properties of ellagic acid in malaria treatment. Antimicrob Agents Chemother, 2009; 53: 1100-6.

29. Reddy MK, Gupta SK, Jacob MR, Khan SI, Ferreira D. Antioxidant, antimalarial and antimicrobial activities of tannin-rich fractions, ellagitannins and phenolic acids from Punica granatum L. Planta Med, 2007; 73: 461-467.

30. Omokhua AG, McGaw LJ, Finnie JF, van Staden J. Chromolaena odorata (L.) R.M. King \& H. Rob. (Asteraceae) in sub-Saharan Africa: A synthesis and review of its medicinal potential. J Ethnopharmacol, 2015.

31. Ganie SA, Yadav SS. Holoptelea integrifolia (Roxb.) Planch: a review of its ethnobotany, pharmacology, and phytochemistry. Biomed Res Int, 2014; 2014: 401213.

32. Zongo F, Ribuot C, Boumendjel A, Guissou I. Botany, traditional uses, phytochemistry and pharmacology of Waltheria indica L. (syn. Waltheria americana): a review. J Ethnopharmacol, 2013; 148: 14-26.

33. Lu Z, Van Wagoner RM, Pond CD, Pole AR, Jensen JB, Blankenship D, Grimberg BT, Kiapranis R, Matainaho TK, Barrows LR, Ireland CM. Myristicyclins A and B: antimalarial procyanidins from Horsfieldia spicata from Papua New Guinea. Org Lett, 2014; 16: 346-9.

34. Apers S, Vlietinck A, Pieters L. Lignans and neolignans as lead compounds. Phytochemistry Reviews 2003; 2: 201-217.

35. Skytte DM, Nielsen SF, Chen M, Zhai L, Olsen CE, Christensen SB. Antimalarial and antiplasmodial activities of norneolignans. Syntheses and SAR. J Med Chem, 2006; 49: 436-40.

36. de Andrade-Neto VF, da Silva T, Lopes LM, do Rosário VE, de Pilla Varotti F, Krettli $\mathrm{AU}$. Antiplasmodial activity of aryltetralone lignans from Holostylis reniformis. Antimicrob Agents Chemother, 2007; 51: 2346-50.

37. da Silva Filho AA, Costa ES, Cunha WR, e Silva ML, Nanayakkara NP, Bastos JK. In vitro antileishmanial and antimalarial activities of tetrahydrofuran lignans isolated from Nectandra megapotamica (Lauraceae). Phytother Res, 2008; 22: 1307-10.

38. Oketch-Rabah HA, Dossaji SF, Christensen SB, Frydenvang K, Lemmich E, Cornett C, Olsen CE, Chen M, Kharazmi A, Theander T. Antiprotozoal compounds from Asparagus africanus. J Nat Prod, 1997; 60: 1017-22. 
39. Mbah JA, Tane P, Ngadjui BT, Connolly JD, Okunji CC, Iwu MM, Schuster BM. Antiplasmodial agents from the leaves of Glossocalyx brevipes. Planta Med, 2004; 70: 437-40.

40. Park WH, Lee SJ, Moon HI. Antimalarial activity of a new stilbene glycoside from Parthenocissus tricuspidata in mice. Antimicrob Agents Chemother, 2008; 52: 34513.

41. Mishra NC, Sharma M, Sharma A. Inhibitory effect of piceatannol, a protein tyrosine kinase inhibitor, on asexual maturation of Plasmodium falciparum. Indian J Exp Biol, 1999; 37: 418-20.

42. Sharma N, Mohanakrishnan D, Shard A, Sharma A, Saima, Sinha AK, Sahal D. Stilbene-chalcone hybrids: design, synthesis, and evaluation as a new class of antimalarial scaffolds that trigger cell death through stage specific apoptosis. J Med Chem, 2012; 55: 297-311.

43. Murakami N, Mostaqul HM, Tamura S, Itagaki S, Horii T, Kobayashi M. New antimalarial flavonol glycoside from Hydrangeae Dulcis Folium. Bioorg Med Chem Lett, 2001; 11: 2445-7.

44. Liu Y, Murakami N, Ji H, Abreu P, Zhang S. Antimalarial Flavonol Glycosides from Euphorbia hirta. Pharmaceutical Biology, 2006; 45: 278-281.

45. [raziose R, Grace MH, Rathinasabapathy T, Rojas-Silva P, Dekock C, Poulev A, Lila MA, Smith P, Raskin I. Antiplasmodial activity of cucurbitacin glycosides from Datisca glomerata (C. Presl) Baill. Phytochemistry, 2013; 87: 78-85.

46. Rodrigues Goulart H, Kimura EA, Peres VJ, Couto AS, Aquino Duarte FA, Katzin AM. Terpenes arrest parasite development and inhibit biosynthesis of isoprenoids in Plasmodium falciparum. Antimicrob Agents Chemother, 2004; 48: 2502-9.

47. Towler MJ, Weathers PJ. Variations in key artemisinic and other metabolites throughout plant development in Artemisia annua L. for potential therapeutic use. Ind Crops Prod, 2015; 67: 185-191.

48. Warhurst DC. Cinchona alkaloids and malaria. Lancet, 1981; 2: 1346.

49. Achan J, Talisuna AO, Erhart A, Yeka A, Tibenderana JK, Baliraine FN, Rosenthal PJ, D'Alessandro U. Quinine, an old anti-malarial drug in a modern world: role in the treatment of malaria. Malaria Journal, 2011; 10.

50. White NJ. Pharmacokinetic and pharmacodynamic considerations in antimalarial dose optimization. Antimicrob Agents Chemother, 2013; 57: 5792-807.

51. Chierrito TP, Aguiar AC, de Andrade IM, Ceravolo IP, Gonçalves RA, de Oliveira AJ, Krettli AU. Anti-malarial activity of indole alkaloids isolated from Aspidosperma olivaceum. Malar J, 2014; 13: 142.

52. Traore M, Guiguemde A, Yago I, Nikiema JB, Tinto H, Dakuyo ZP, Ouedraogo JB, Guissou IP, Guiguemde TR. Investigation of antiplasmodial compounds from two plants, Cochlospermum tictorium A. Rich and Gardenia Sokotensis Hutch. African Journal of Traditional, Complementary and Alternative Medicines, 2006; 3: 34-41.

53. Endale M, Ekberg A, Alao JP, Akala HM, Ndakala A, Sunnerhagen P, Erdélyi M, Yenesew A. Anthraquinones of the roots of Pentas micrantha. Molecules, 2012; 18: 311-21.

54. Chanphen R, Thebtaranonth Y, Wanauppathamkul S, Yuthavong Y. Antimalarial principles from Artemisia indica. J Nat Prod, 1998; 61: 1146-7.

55. Tasdemir D, Tierney M, Sen R, Bergonzi MC, Demirci B, Bilia AR, Baser KH, Brun R, Chatterjee M. Antiprotozoal Effect of Artemisia indica Extracts and Essential Oil. Planta Med, 2015; 81: 1029-37.

56. Mannan A, Ahmed I, Arshad W, Asim MF, Qureshi RA, Hussain I, Mirza B. Survey of artemisinin production by diverse Artemisia species in northern Pakistan. Malar J, 2010; 9: 310.

57. Okokon JE, Ettebong E, Antia BS. In vivo antimalarial activity of ethanolic leaf extract of Stachytarpheta cayennensis. Indian J Pharmacol, 2008; 40: 111-3.

58. Froelich S, Gupta MP, Siems K, Jenett-Siems K. Phenylethanoid glycosides from Stachytarpheta cayennensis (Rich.) Vahl, Verbenaceae, a traditional 
antimalarial medicinal plant. Revista Brasileira de Farmacognosia, 2008; 18: 517520.

59. Garcia-Alvarez MC, Moussa I, Njomnang Soh $P$, Nongonierma R, Abdoulaye A, Nicolau-Travers ML, Fabre A, Wdzieczak-Bakala J, Ahond A, Poupat C, Ikhiri K, Benoit-Vical F. Both plants Sebastiania chamaelea from Niger and Chrozophora senegalensis from Senegal used in African traditional medicine in malaria treatment share a same active principle. J Ethnopharmacol, 2013; 149: 676-84.

60. Ajala TO, Igwilo $\mathrm{Cl}$, Oreagba IA, Odeku OA. The antiplasmodial effect of the extracts and formulated capsules of Phyllanthus amarus on Plasmodium yoelii infection in mice. Asian Pac J Trop Med, 2011; 4: 283-7.

61. Kensil CR, Patel U, Lennick M, Marciani D. Separation and characterization of saponins with adjuvant activity from Quillaja saponaria Molina cortex. J Immunol, 1991; 146: 431-7.

62. Kaslow DC, Biernaux S. RTS,S: Toward a first landmark on the Malaria Vaccine Technology Roadmap. Vaccine, 2015.

63. Penny MA, Verity R, Bever CA, Sauboin C, Galactionova K, Flasche S, White MT, Wenger EA, Van de Velde N, Pemberton-Ross P, Griffin JT, Smith TA, Eckhoff PA, Muhib F, Jit M, Ghani AC. Public health impact and cost-effectiveness of the RTS,S/AS01 malaria vaccine: a systematic comparison of predictions from four mathematical models. Lancet, 2015.

64. Kebenei J, Ndalut P, Sabah A. Anti-plasmodial activity of Nortrachelogenin from the root bark of Carissa edulis (vahl). International Journal Of Applied Research In Natural Products 2011; 4: 1-5.

65. Brown GD, Liang GY, Sy LK. Terpenoids from the seeds of Artemisia annua. Phytochemistry, 2003; 64: 303-23.

66. Paddon CJ, Keasling JD. Semi-synthetic artemisinin: a model for the use of synthetic biology in pharmaceutical development. Nat Rev Microbiol, 2014; 12: 355-67.

67. Gordi T, Huong DX, Hai TN, Nieu NT, Ashton M. Artemisinin pharmacokinetics and efficacy in uncomplicated-malaria patients treated with two different dosage regimens. Antimicrob Agents Chemother, 2002; 46: 1026-31.

68. Medhi B, Patyar S, Rao RS, Byrav D S P, Prakash A. Pharmacokinetic and toxicological profile of artemisinin compounds: an update. Pharmacology, 2009; 84: 323-32.

69. Visser BJ, van Vugt M, Grobusch MP. Malaria: an update on current chemotherapy. Expert Opin Pharmacother, 2014; 15: 2219-54.

70. Amuka O, Okemo P, Machocho A, Mbugua P, Njagi NME, Nyamache A. The role of phytomedicine in the challenges of emerging, re-emerging diseases; and pathogens resistance to antibiotics. International Journal of Herbal Medicine, 2013; 1: 92-101.

71. Gunasekaran T, Haile T, Nigusse T, Dhanaraju MD. Nanotechnology: an effective tool for enhancing bioavailability and bioactivity of phytomedicine. Asian Pac J Trop Biomed, 2014; 4: S1-7.

72. Ansari MT, Pervez H, Shehzad MT, Saeed-ul-Hassan S, Mehmood Z, Shah SN, Razi MT, Murtaza G. Improved physicochemical characteristics of artemisinin using succinic acid. Acta Pol Pharm, 2014; 71: 451-62.

73. Santosh P, Bhat M, Toppo E, Savia A, Purohit S. Solid dispersion of artemisisin. The Pharmacist, 2008; 3: 15-17.

74. Räth K, Taxis K, Walz G, Gleiter CH, Li SM, Heide L. Pharmacokinetic study of artemisinin after oral intake of a traditional preparation of Artemisia annua L. (annual wormwood). Am J Trop Med Hyg, 2004; 70: 128-32.

75. Wang S, Su R, Nie S, Sun M, Zhang J, Wu D, Moustaid-Moussa N. Application of nanotechnology in improving bioavailability and bioactivity of diet-derived phytochemicals. J Nutr Biochem, 2014; 25: 363-76.

76. Shoji Y, Nakashima H. Nutraceutics and delivery systems. J Drug Target, 2004; 12: 385-91. 
77. Kumari A, Yadav SK, Pakade YB, Singh B, Yadav SC. Development of biodegradable nanoparticles for delivery of quercetin. Colloids Surf B Biointerfaces, 2010; 80: 184-92.

78. Wang W, Zhao X, Hu H, Chen D, Gu J, Deng Y, Sun J. Galactosylated solid lipid nanoparticles with cucurbitacin B improves the liver targetability. Drug Deliv, 2010; 17: 114-22.

79. Jeetah R, Bhaw-Luximon A, Jhurry D. Nanopharmaceutics: phytochemical-based controlled or sustained drug-delivery systems for cancer treatment. J Biomed Nanotechnol, 2014; 10: 1810-40.

80. Stella VJ, Nti-Addae KW. Prodrug strategies to overcome poor water solubility. Adv Drug Deliv Rev, 2007; 59: 677-94.

81. Heimbach TF, D.Kaddoumi, A,. Overcoming Poor Aqueous Solubility of Drugs for Oral Delivery. In: Stella VJB, R. T.Hageman, M. J.Oliyai, R.Maag, H.Tilley, J. W., ed.^eds., Prodrugs: Challenges and Rewards Part 1. Springer New York, 2007; pp. 157-215.

82. Sawant SS, Singh KK. Nanophytomedicine: Current and Future Perspectives. In: ed.^eds., NanoPharmaceuticals, 2015.

83. Pifferi G. Silipide: A New Bioavailable Complex of Silybin. Planta Medica, 1991; 57: A12.

84. Bhosale AP, Patil A, Swami M. Herbosomes as a novel drug delivery system for absorption enhancement. World Journal of Pharmacy and Pharmaceutical Sciences, 2016; 5: 345-355.

85. Ekor $\mathrm{M}$. The growing use of herbal medicines: issues relating to adverse reactions and challenges in monitoring safety. Front Pharmacol, 2014; 4: 177.

86. Mohamed I, Shuid A, Borhanuddin B, Fozi N. The Application of Phytomedicine in Modern Drug Development. The Internet Journal of Herbal and Plant Medicine, 2012; 1.

87. Goldman P. Herbal medicines today and the roots of modern pharmacology. Ann Intern Med, 2001; 135: 594-600.

88. Sharma AK, Kumar R, Mishra A, Gupta R. Problems associated with clinical trials of Ayurvedic medicines. Brazilian Journal of Pharmacognosy, 2010; 20: 276-281.

89. Vale VV, Vilhena TC, Trindade RC, Ferreira MR, Percário S, Soares LF, Pereira WL, Brandão GC, Oliveira AB, Dolabela MF, De Vasconcelos F. Anti-malarial activity and toxicity assessment of Himatanthus articulatus, a plant used to treat malaria in the Brazilian Amazon. Malar J, 2015; 14: 132.

90. Gupta S, Kesarla R, Omri A. Formulation strategies to improve the bioavailability of poorly absorbed drugs with special emphasis on self-emulsifying systems. ISRN Pharm, 2013; 2013: 848043.

91. Urbán $P$, Fernàndez-Busquets X. Nanomedicine against malaria. Curr Med Chem, 2014; 21: 605-29.

92. Santos-Magalhães NS, Mosqueira VC. Nanotechnology applied to the treatment of malaria. Adv Drug Deliv Rev, 2010; 62: 560-75.

93. Cho K, Wang X, Nie S, Chen ZG, Shin DM. Therapeutic nanoparticles for drug delivery in cancer. Clin Cancer Res, 2008; 14: 1310-6.

94. Ansari TN, Mahmood A, Khattak BK, Rasul S, Syed AS. Toxicity profile and objective response of paclitaxel in metastatic breast cancer. J Coll Physicians Surg Pak, 2005; 15: 200-3.

95. Konno T, Watanabe J, Ishihara K. Enhanced solubility of paclitaxel using watersoluble and biocompatible 2-methacryloyloxyethyl phosphorylcholine polymers. J Biomed Mater Res A, 2003; 65: 209-14.

96. Allen TM, Hansen C, Martin F, Redemann C, Yau-Young A. Liposomes containing synthetic lipid derivatives of poly(ethylene glycol) show prolonged circulation halflives in vivo. Biochim Biophys Acta, 1991; 1066: 29-36.

97. Nussbaumer S, Bonnabry P, Veuthey JL, Fleury-Souverain S. Analysis of anticancer drugs: a review. Talanta, 2011; 85: 2265-89. 
98. Corti A, Pastorino F, Curnis F, Arap W, Ponzoni M, Pasqualini R. Targeted drug delivery and penetration into solid tumors. Med Res Rev, 2012; 32: 1078-91.

99. Jiang T, Zhang Z, Zhang Y, Lv H, Zhou J, Li C, Hou L, Zhang Q. Dual-functional liposomes based on $\mathrm{pH}$-responsive cell-penetrating peptide and hyaluronic acid for tumor-targeted anticancer drug delivery. Biomaterials, 2012; 33: 9246-58.

100. Thistlethwaite AJ, Leeper DB, Moylan DJ, Nerlinger RE. pH distribution in human tumors. Int J Radiat Oncol Biol Phys, 1985; 11: 1647-52.

101. Bilensoy E, Gürkaynak O, Doğan AL, Hincal AA. Safety and efficacy of amphiphilic beta-cyclodextrin nanoparticles for paclitaxel delivery. Int J Pharm, 2008; 347: 163-70.

102. Yoshizawa Y, Kono Y, Ogawara K, Kimura T, Higaki K. PEG liposomalization of paclitaxel improved its in vivo disposition and anti-tumor efficacy. Int J Pharm, 2011; 412: 132-41.

103. Safari J, Zarnegar Z. Advanced drug delivery systems: Nanotechnology of health design A review. Journal of Saudi Chemical Society, 2014; 18: 85-89.

104. Gong J, Chen M, Zheng Y, Wang S, Wang Y. Polymeric micelles drug delivery system in oncology. J Control Release, 2012; 159: 312-23.

105. Prabhu RH, Patravale VB, Joshi MD. Polymeric nanoparticles for targeted treatment in oncology: current insights. Int J Nanomedicine, 2015; 10: 1001-18.

106. Joralemon MJ, McRae S, Emrick T. PEGylated polymers for medicine: from conjugation to self-assembled systems. Chem Commun (Camb), 2010; 46: 1377-93.

107. Peer D, Karp JM, Hong S, Farokhzad OC, Margalit R, Langer R. Nanocarriers as an emerging platform for cancer therapy. Nat Nanotechnol, 2007; 2: 751-60.

108. Li L, Huh KM. Polymeric nanocarrier systems for photodynamic therapy. Biomater Res, 2014; 18: 19.

109. Yellepeddi VK, Kumar A, Palakurthi S. Surface modified poly(amido)amine dendrimers as diverse nanomolecules for biomedical applications. Expert Opin Drug Deliv, 2009; 6: 835-50.

110. Wolinsky JB, Grinstaff MW. Therapeutic and diagnostic applications of dendrimers for cancer treatment. Adv Drug Deliv Rev, 2008; 60: 1037-55.

111. Tomalia DA, Reyna LA, Svenson S. Dendrimers as multi-purpose nanodevices for oncology drug delivery and diagnostic imaging. Biochem Soc Trans, 2007; 35: 61-7.

112. Boas U, B. CJ, H. HPM. Dendrimers in Medicine and Biotechnology: New Molecular Tools. The Royal Society of Chemistry. : Cambridge, United Kingdom 2006.

113. [Isea R, Hoebeke J, Mayo-García R. Designing a Peptide-dendrimer for Use as a Synthetic Vaccine against Plasmodium Falciparum. American Journal of Bioinformatics and Computational Biology, 2013; 1: 1-8

114. Bhadra D, Bhadra S, Jain NK. PEGylated peptide-based dendritic nanoparticulate systems for delivery of artemether. Journal of Drug Delivery Science and Technology, 2005; 15:65-73

115. Bhadra D, Bhadra S, Jain NK. Pegylated lysine based copolymeric dendritic micelles for solubilization and delivery of artemether. J Pharm Pharm Sci, 2005; 8(3):467-82.

116. Croy SR, Kwon GS. Polymeric micelles for drug delivery. Curr Pharm Des, 2006; 12: 4669-84.

117. Dahmani FZ, Yang H, Zhou J, Yao J, Zhang T, Zhang Q. Enhanced oral bioavailability of paclitaxel in pluronic/LHR mixed polymeric micelles: preparation, in vitro and in vivo evaluation. Eur J Pharm Sci, 2012; 47: 179-89.

118. Zhao X, Poon Z, Engler AC, Bonner DK, Hammond PT. Enhanced stability of polymeric micelles based on postfunctionalized poly(ethylene glycol)-b-poly( $\gamma$ propargyl L-glutamate): the substituent effect. Biomacromolecules, 2012; 13: 131522. 
119. Inoue T, Yamashita $Y$, Nishihara M, Sugiyama S, Sonoda $Y$, Kumabe T, Yokoyama M, Tominaga $\mathrm{T}$. Therapeutic efficacy of a polymeric micellar doxorubicin infused by convection-enhanced delivery against intracranial $9 \mathrm{~L}$ brain tumor models. Neuro Oncol, 2009; 11: 151-7.

120. Xu W, Ling P, Zhang T. Polymeric micelles, a promising drug delivery system to enhance bioavailability of poorly water-soluble drugs. J Drug Deliv, 2013; 2013: 340315.

121. McMillan J, Batrakova E, Gendelman HE. Cell delivery of therapeutic nanoparticles. Prog Mol Biol Transl Sci, 2011; 104: 563-601.

122. Cui L, Miao J. Cytotoxic effect of curcumin on malaria parasite Plasmodium falciparum: inhibition of histone acetylation and generation of reactive oxygen species. Antimicrob Agents Chemother, 2007; 51: 488-94.

123. Chakrabarti R, Rawat PS, Cooke BM, Coppel RL, Patankar S. Cellular effects of curcumin on Plasmodium falciparum include disruption of microtubules. PLoS One, 2013; 8: e57302.

124. Lv L, Shen Y, Li M, Xu X, Guo S, Huang S. Novel 4-arm poly(ethylene glycol)block-poly(anhydride-esters) amphiphilic copolymer micelles loading curcumin: preparation, characterization, and in vitro evaluation. Biomed Res Int, 2013; 2013: 507103.

125. Aw MS, Kurian M, Losic D. Polymeric micelles for multidrug delivery and combination therapy. Chemistry, 2013; 19: 12586-601.

126. Kopeček J. Polymer-drug conjugates: origins, progress to date and future directions. Adv Drug Deliv Rev, 2013; 65: 49-59.

127. Kumar S, Singh RK, Sharma R, Murthy RS, Bhardwaj TR. Design, synthesis and evaluation of antimalarial potential of polyphosphazene linked combination therapy of primaquine and dihydroartemisinin. Eur J Pharm Sci, 2014; 66C: 123-137.

128. Yang R, Zhang S, Kong D, Gao X, Zhao Y, Wang Z. Biodegradable polymercurcumin conjugate micelles enhance the loading and delivery of low-potency curcumin. Pharm Res, 2012; 29: 3512-25.

129. Domínguez A, Suárez-Merino B, Goñi-de-Cerio F. Nanoparticles and bloodbrain barrier: the key to central nervous system diseases J Nanosci Nanotechnol. 2014 Jan;14(1):766-79.

130. Patel M, Souto EB, Singh KK. Advances in brain drug targeting and delivery: limitations and challenges of solid lipid nanoparticles, Expert Opin. Drug Deliv, 2013;10: 889-905.

131. Douglas S. Watson, Aaron N. Endsley, Leaf Huang Design considerations for liposomal vaccines: Influence of formulation parameters on antibody and cellmediated immune responses to liposome associated antigens, Vaccine. 2012 March 16; 30(13): 2256-2272.

132. Feeney OM, Williams HD, Pouton CW, Porter CJ. 'Stealth' lipid-based formulations: poly(ethylene glycol)-mediated digestion inhibition improves oral bioavailability of a model poorly water soluble drug. J Control Release, 2014; 192: 219-27.

133. Bunker A, Magarkar A, Viitala T. Rational design of liposomal drug delivery systems, a review: Combined experimental and computational studies of lipid membranes, liposomes and their PEGylation. Biochim Biophys Acta, 2016.

134. Righeschi C, Coronnello M, Mastrantoni A, Isacchi B, Bergonzi MC, Mini E, Bilia AR. Strategy to provide a useful solution to effective delivery of dihydroartemisinin: development, characterization and in vitro studies of liposomal formulations. Colloids Surf B Biointerfaces, 2014; 116: 121-7.

135. Aditya NP, Chimote G, Gunalan K, Banerjee R, Patankar S, Madhusudhan B. Curcuminoids-loaded liposomes in combination with arteether protects against Plasmodium berghei infection in mice. Exp Parasitol, 2012; 131: 292-9.

136. Isacchi B, Bergonzi MC, Grazioso M, Righeschi C, Pietretti A, Severini C, 
Bilia AR. Artemisinin and artemisinin plus curcumin liposomal formulations:

Enhanced antimalarial efficacy against Plasmodium berghei-infected mice. Eur J

Pharm \& Biopharm. 2012;80:528-34

137. Uner M, Yener G. Importance of solid lipid nanoparticles (SLN) in various

administration routes and future perspectives. Int J Nanomedicine, 2007; 2: 289-300.

138. Gupta R, Singh KK. Solid lipid drug carriers in cancer chemotherapy.

iSmithers Publications: London 2011.

139. Hollander D, Koyama S, Dadufalza V, Tran DQ, Krugliak P, Ma T, Ling KY. Polyethylene glycol 900 permeability of rat intestinal and colonic segments in vivo and brush border membrane vesicles in vitro. J Lab Clin Med, 1989; 113: 505-15.

140. [Zheng J, Wan Y, Elhissi A, Zhang Z, Sun X. Targeted paclitaxel delivery to tumors using cleavable PEG-conjugated solid lipid nanoparticles. Pharm Res, 2014; 31: 2220-33.

141. Gupta Y, Jain A, Jain SK. Transferrin-conjugated solid lipid nanoparticles for enhanced delivery of quinine dihydrochloride to the brain. J Pharm Pharmacol, 2007; 59: $935-40$

142. Anand P, Kunnumakkara AB, Newman RA, Aggarwal BB. Bioavailability of curcumin: problems and promises. Mol Pharm, 2007; 4: 807-18.

143. Kumar A, Ahuja A, Ali J, Baboota S. Curcumin-loaded lipid nanocarrier for improving bioavailability, stability and cytotoxicity against malignant glioma cells. Drug Deliv, 2015: 1-16.

144. Righeschi C, Bergonzi MC, Isacchi B, Bazzacalupi C, Gratteri P, Bilia AR. Enhanced curcumin permeability by SLN formulation: The PAMPA approach. LWT Food Science and Technology, 2016; 66: 478-483.

145. Memvanga PB, Coco R, Préat V. An oral malaria therapy: curcumin-loaded lipid-based drug delivery systems combined with $\beta$-arteether. J Control Release, 2013; 172: 904-13.

146. Nandakumar DN, Nagaraj VA, Vathsala PG, Rangarajan P, Padmanaban G. Curcumin-artemisinin combination therapy for malaria. Antimicrob Agents Chemother, 2006; 50: 1859-60.

147. Mimche PN, Taramelli D, Vivas L. The plant-based immunomodulator curcumin as a potential candidate for the development of an adjunctive therapy for cerebral malaria. Malar J, 2011; 10 Suppl 1: S10.

148. Nayak AP, Tiyaboonchai W, Patankar S, Madhusudhan B, Souto EB. Curcuminoids-loaded lipid nanoparticles: novel approach towards malaria treatment. Colloids Surf B Biointerfaces, 2010; 81: 263-73.

149. Iqbal MA, Md S, Sahni JK, Baboota S, Dang S, Ali J. Nanostructured lipid carriers system: recent advances in drug delivery.J Drug Target. 2012; 20(10):81330.

150. Joshi M, Pathak S, Sharma S, Patravale V. Design and in vivo pharmacodynamic evaluation of nanostructured lipid carriers for parenteral delivery of artemether: Nanoject. Int J Pharmaceutics, 2008;364:119-26.

151. Chinaeke EE, Chime SA, Ogbonna JDN, Attama AA, Müller-Goymann CC, Okore VC. Evaluation of dika wax-soybean oil-based artesunate-loaded lipospheres: in vitro-in vivo correlation studies. Journal of MicroencapsulationJournal of Microencapsulation, 2014; 31: 796-804.

152. Hörmann K, Zimmer A. Drug delivery and drug targeting with parenteral lipid nanoemulsions - A review. Journal of Controlled Release, 2016; 223: 85-98.

153. Dwivedi P, Khatik R, Chaturvedi P, Khandelwal K, Taneja I, Raju KS, Dwivedi H, Singh SK, Gupta PK, Shukla P, Tripathi P, Singh S, Tripathi R, Wahajuddin, Paliwal SK, Dwivedi AK, Mishra PR. Arteether nanoemulsion for enhanced efficacy 
against Plasmodium yoelii nigeriensis malaria: an approach by enhanced

bioavailability. Colloids Surf B Biointerfaces, 2015; 126: 467-75.

154. Joshi M, Pathak S, Sharma S, Patravale V. Solid microemulsion

preconcentrate (NanOsorb) of artemether for effective treatment of malaria. Int J

Pharm, 2008; 362: 172-8.

155. He H, Pham-Huy LA, Dramou P, Xiao D, Zuo P, Pham-Huy C. Carbon

nanotubes: applications in pharmacy and medicine. Biomed Res Int, 2013; 2013:

578290.

156. Ali-Boucetta $\mathrm{H}$, Kostarelos $\mathrm{K}$. Pharmacology of carbon nanotubes:

toxicokinetics, excretion and tissue accumulation. Adv Drug Deliv Rev, 2013; 65: 2111-9.

157. Beg S, Samad A, Nazish I, Sultana R, Rahman M, Ahmad MZ, Akbar M. Colloidal drug delivery systems in vaccine delivery. Curr Drug Targets, 2013; 14: 123-37.

158. Martin CR, Kohli P. The emerging field of nanotube biotechnology. Nat Rev Drug Discov, 2003; 2: 29-37.

159. Zhang W, Zhang Z, Zhang Y. The application of carbon nanotubes in target drug delivery systems for cancer therapies. Nanoscale Res Lett, 2011; 6: 555.

160. Shiba K. Functionalization of carbon nanomaterials by evolutionary molecular engineering: potential application in drug delivery systems. J Drug Target, 2006; 14: 512-8.

161. Bianco A. Carbon nanotubes for the delivery of therapeutic molecules. Expert Opin Drug Deliv, 2004; 1: 57-65.

162. Bianco A, Kostarelos K, Prato M. Applications of carbon nanotubes in drug delivery. Curr Opin Chem Biol, 2005; 9: 674-9.

163. Gottardi R, Douradinha B. Carbon nanotubes as a novel tool for vaccination against infectious diseases and cancer. J Nanobiotechnology, 2013; 11: 30.

164. Purcell AW, McCluskey J, Rossjohn J. More than one reason to rethink the use of peptides in vaccine design. Nat Rev Drug Discov, 2007; 6: 404-14.

165. Kagan VE, Konduru NV, Feng W, Allen BL, Conroy J, Volkov Y, Vlasova II, Belikova NA, Yanamala N, Kapralov A, Tyurina YY, Shi J, Kisin ER, Murray AR, Franks J, Stolz D, Gou P, Klein-Seetharaman J, Fadeel B, Star A, Shvedova AA. Carbon nanotubes degraded by neutrophil myeloperoxidase induce less pulmonary inflammation. Nat Nanotechnol, 2010; 5: 354-9.

166. Jain P, Chakma B, Patra S, Goswami P. Potential biomarkers and their applications for rapid and reliable detection of malaria. Biomed Res Int, 2014; 2014 : 852645.

167. Singh S, Konwar B. Carbon Nanotube Assisted Drug Delivery of the AntiMalarial Drug Artemesinin and Its Derivatives - A Theoretical Nanotechnology Approach. Journal of Bionanoscience, 2013; 7: 630-636.

168. Hernando A, Crespo P, García MA. Metallic magnetic nanoparticles. ScientificWorldJournal, 2005; 5: 972-1001.

169. Mody VV, Siwale R, Singh A, Mody HR. Introduction to metallic nanoparticles. J Pharm Bioallied Sci, 2010; 2: 282-9.

170. Pumera M. Graphene, Carbon Nanotubes and Nanoparticles in Cell Metabolism. Curr Drug Metab, 2012.

171. Sannella AR, Casini A, Gabbiani C, Messori L, Bilia AR, Vincieri FF, Majori G, Severini C. New uses for old drugs. Auranofin, a clinically established antiarthritic metallodrug, exhibits potent antimalarial effects in vitro: Mechanistic and pharmacological implications. FEBS Lett, 2008; 582: 844-7.

172. Karthik L, Kumar G, Keswani T, Bhattacharyya A, Reddy BP, Rao KV. Marine actinobacterial mediated gold nanoparticles synthesis and their antimalarial activity. Nanomedicine: Nanotech, Bio and Med. 2013;9:951-60.

173. Al-Deen FN, Ho J, Selomulya C, Ma C, Coppel R. Superparamagnetic nanoparticles for effective delivery of malaria DNA vaccine. Langmuir, 2011; 27: 
174. Shegokar RM, R.H. Nanocrystals: industrially feasible multifunctional formulation technology for poorly soluble actives. International Journal of Pharmaceutics, 2010; 399: 129-139.

175. Chingunpitak J, Puttipipatkhachorn S, Chavalitshewinkoon-Petmitr P, Tozuka $\mathrm{Y}$, Moribe $\mathrm{K}$, Yamamoto K. Formation, physical stability and in vitro antimalarial activity of dihydroartemisinin nanosuspensions obtained by co-grinding method. Drug Dev Ind Pharm, 2008; 34: 314-22.

176. Ghosh A, Banerjee T, Bhandary S, Surolia A. Formulation of nanotized curcumin and demonstration of its antimalarial efficacy. Int J Nanomedicine, 2014; 9: 5373-87.

177. Grobler A, Kotze A, Du Plessis J eds. The design of a skin-friendly carrier for cosmetic compounds using Pheroid ${ }^{\mathrm{TM}}$ Technology 2008.

178. Steyn JD, Wiesner L, du Plessis LH, Grobler AF, Smith PJ, Chan WC, Haynes RK, Kotzé AF. Absorption of the novel artemisinin derivatives artemisone and artemiside: potential application of Pheroid ${ }^{\mathrm{TM}}$ technology. Int J Pharm, 2011; 414: $260-6$.

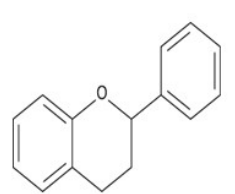

(a)<smiles>O=C(O)c1cc(O)c(O)c(O)c1</smiles>

(f)

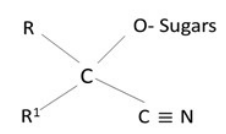

(k)

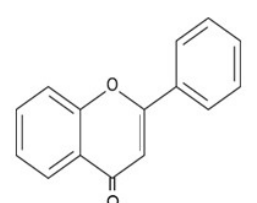

(b)

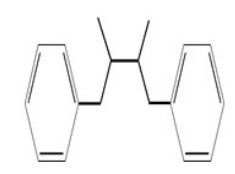

(g)

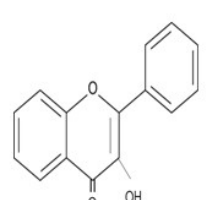

(c)

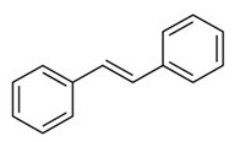

(h)

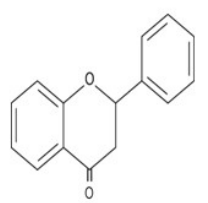

(d)

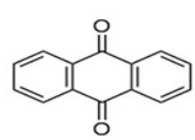

(i)

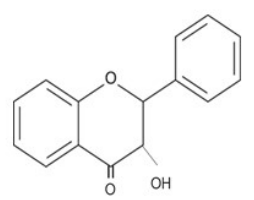

(e)<smiles>O=c1ccc2ccccc2o1</smiles>

(j)

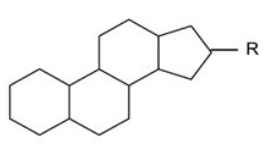

(I)

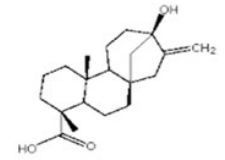

(m)

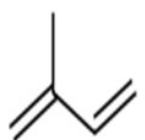

(n)

Figure 1: Chemical structures of (a) polyphenols (b) flavone (c) flavonol (d) flavanone (e) flavanonol (f) gallic acid (g) dibenzylbutane skeleton, the base structure for several lignans $(h)$ base structure of stilbenes (i) anthraquinones (j) coumarins (k) cyanogenic glycosides (l) 
steroid structure base for saponin glycosides (m) steviol (n) isoprene structure, the base for terpenoids

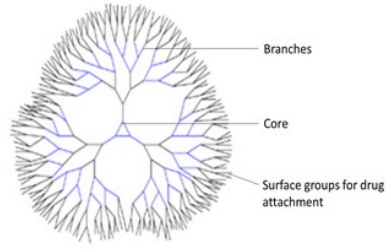

(a)

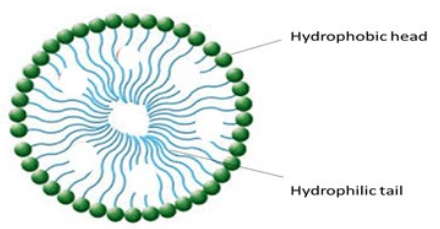

(b)

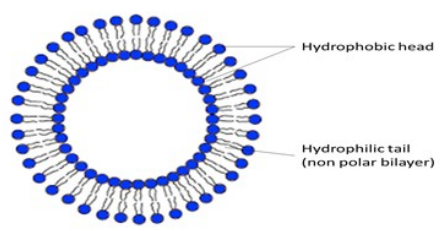

(c)

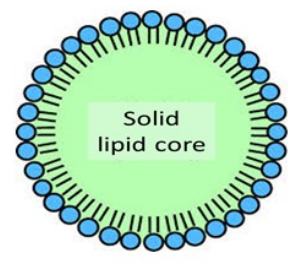

(d)

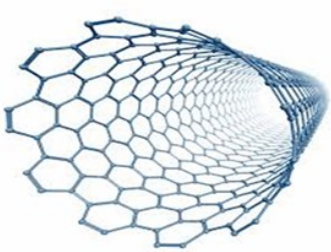

(e)

Figure 2: Illustration of nanotechnology-based delivery systems (a) poly(amido)amine (PAMAM) dendrimer (b) polymeric micelle (c) liposomes (d) solid lipid nanoparticle (e) carbon nanotube 